\title{
La insostenibilidad de los desarrollos de vivienda de interés social en México: una aproximación desde el pensamiento de diseño. Caso de estudio: Tlajomulco de Zúñiga, Jalisco
}

\author{
Citlalli Elizabeth Calderón Villegas ${ }^{1}$ | Hermilo Salas Espíndola ${ }^{2}$ | Patricia Ávila García ${ }^{3}$ \\ Recibido: 29-04-2019 | en su versión final: 03-01-2020
}

Resumen

\begin{abstract}
El principal objetivo de este trabajo es: Identificar los factores que determinan el deterioro de los desarrollos de Vivienda de Interés Social (VIS) en México dentro de la relación ciudad-medio ambiente. La metodología se divide en dos apartados: El primero consiste en el análisis del ciclo de gestión de producción de la VIS y su fundamentación teórica. El segundo, es una aproximación empírica a la problemática de este tipo de vivienda a través del pensamiento de diseño con base en las siguientes etapas: 1) Empatía con el usuario, 2) Definición del problema, 3) Abstracción de soluciones, 4) Conceptualización de un modelo y, 5) Evaluación del desempeño. El deterioro ambiental del contexto urbano de la vivienda de interés social en las ciudades mexicanas es el resultado de: por un lado, la disminución de intervención del Estado sobre las políticas que regulan su gestión y la especulación del suelo y, por otro lado, de la dilución de la responsabilidad entre el municipio, urbanizadores, constructores y una normatividad débil en cuestiones de bienestar sobre la calidad de la vivienda y su entorno. Este trabajo es un estudio de caso que aborda la complejidad del problema de la VIS en México. Además, representa una propuesta metodológica para abordar la insostenibilidad urbano-ambiental de la producción de este tipo de infraestructura con bases epistemológicas multidisciplinares, como lo son: el pensamiento de diseño y la gestión de proyectos.
\end{abstract}

Palabras clave: Ciclo de gestión de proyectos; deterioro urbano-ambiental; complejidad; planeamiento urbano

Citación

Calderón Villegas, C. et al. (2020). La insostenibilidad de los desarrollos de vivienda de interés social en México: una aproximación desde el pensamiento de diseño. Caso de estudio: Tlajomulco de Zúñiga, Jalisco. ACE: Architecture, City and Environment, 14(42), 8256. DOI: http://dx.doi.org/10.5821/ace.14.42.8256

\footnotetext{
${ }^{1}$ M.C. en Gestión Ambiental, Arquitecta, Doctoranda en la Universidad Nacional Autónoma de México, UNAM, por el Instituto de Ecología (ORCID: 0000-0001-8111-8120); ${ }^{2}$ Dr. Arquitecto. Catedrático de la Facultad de Arquitectura y Urbanismo de la Universidad Nacional Autónoma de México, UNAM (ORCID: 0000-00026737-4061); ${ }^{3}$ Dra. Investigadora Titula B del Instituto de Investigaciones en Ecosistemas y Sustentabilidad de la Universidad Nacional Autónoma de México, UNAM (ORCID: 0000-0002-4268-8777; Researcher ID: B6444-2016). Correo de contacto: calderon.citlalli@gmail.com
}

ACE, 14. (42) CC BY-ND 3.0 ES | UPC Barcelona, España | La insostenibilidad de los desarrollos de vivienda de interés social en México: una aproximación desde el pensamiento de diseño. Caso de estudio: Tlajomulco de Zúninga, Jalisco. DOI http://dx.doi.org/10.5821/ace.14.42.8256 


\title{
Unsustainability of social housing settlements in México: an approach from design thinking. Case study: Tlajomulco de Zúñiga, Jalisco
}

Abstract

\begin{abstract}
The main objective of this work is to identify the drivers of deterioration of social housing settlements in México within the city-environment relationship. The methodology is divided into two sections: theoretical foundation and empirical data analysis. First part consists in analyzing the housing production management cycle based on its policies and administrative procedures, and second part is an empirical approach to the problematic through design thinking considering the following stages: 1) Empathy with the user, 2) Problem definition, 3) Solution abstraction, 4) Conceptualization of a model and, 5) Performance assessment. Environmental deterioration of urban context of social housing in mexican cities is a result of: on one hand, decrease of State intervention over legislation and policies that regulate land speculation and social housing production and, on the other hand, the dilution over the responsibility of built environment between the municipality, developers, contractors and a weak regulation on welfare issues about the quality of social housing and its environment. This paper is a case study wich addresses the complexity of social housing production. It represents a methodological proposal to study the urban-environmental unsustainability of social housing settlements over multidisciplinary epistemological bases, such as: design thinking and project management.
\end{abstract}

Keywords: Project management cycle; urban-environmental deterioration; complexity; urban planning

\section{Introducción}

Los hábitos de consumo adoptados por la sociedad post-industrial han acelerado el deterioro de los sistemas ecológicos de soporte de vida. Un factor determinante del deterioro es el consumo de suelo productivo de servicios eco-sistémicos de regulación de los ciclos biogeoquímicos. Del año 1950 a 1999 la población creció un 130\% y se estima que para el año 2030 habrá crecido un 42\% más (Naciones Unidas, 2018), consecuentemente se prevé un incremento en la demanda de uso de recursos naturales, por ejemplo: el suelo productivo. Las necesidades de la ciudad en crecimiento demandan el incremento de uso de capital físico, natural y social; generalmente las ciudades no están preparadas ni son planeadas para recibir un crecimiento constante de habitantes y su estructura es moldeada en función de las presiones político-económicas a las que se ve expuesta. Una de estas presiones es la demanda de vivienda. La presión se intensifica a la par de la demanda, entonces los gobiernos se ven rebasados en su capacidad de respuesta para producir vivienda y también, en su capacidad de solventar el gasto que ello representa.

En la modernidad, América fue escenario de la construcción de masivos desarrollos de vivienda social, no así, escenario de proyectos exitosos. Al hablar de arquitectura enfocada en la vivienda social, el pensamiento moderno -que priorizó la eficiencia y la estandarización-, se materializó en

ACE, 14. (42) CC BY-ND 3.0 ES | UPC Barcelona, España | La insostenibilidad de los desarrollos de vivienda de interés social 
estructuras masivas repetitivas buscando optimizar recursos en la construcción y en el mantenimiento. La optimización del espacio se tradujo en la compresión de áreas con el propósito de otorgar flexibilidad de uso y ocupación (Canales, 2017). Algunos ejemplos son: 1) Pruitt-lgoe en St. Louis, Missouri - año 1952, 3,000 departamentos; 2) Conjunto 23 de enero en Caracas, Venezuela año 1957, 9,000 unidades; 3) Tlatelolco en México - año 1964, 15,000 unidades y; 4) PREVI —Proyecto Experimental de Vivienda- en Lima, Perú, que en 1968 inició como propuesta para solucionar la demanda de vivienda de bajo coste y la problemática de la vivienda informal. Estos fueron los últimos intentos directos de los gobiernos por proporcionar una base de buena planeación y arquitectura, pues las prioridades de las ciudades en América Latina son cambiantes y el coste de edificar tan rápido y en gran volumen no es sostenible para los países en desarrollo. Se optó entonces por dejar el desarrollo inmobiliario en manos del libre mercado (McGuirk, 2015).

En la actualidad, los conjuntos habitacionales conceptualizados con premisas de modernidad, se han convertido en focos de problemas sociales pues en su planeación no fueron considerados aspectos como: la administración del espacio público, la proyección de las necesidades de la población a través del tiempo, el hacinamiento de familias en una residencia, el incremento de los índices de inseguridad - las curvas migratorias. Así, con la liberación del mercado, el concepto de la vivienda social que surgió bajo el cobijo del pensamiento moderno fue tergiversado hasta mermar la calidad de la vivienda y su contexto urbano a costa de la máxima rentabilidad (Canales, 2017). "[...] Esta misma ecuación fue la que, décadas más tarde, destruyó la periferia de las ciudades y su entorno natural, y es la misma que utilizan las nuevas políticas de densificación urbana que amenazan las zonas céntricas" (Canales, 2017, pág. 41). A la luz de estos antecedentes, debemos recapacitar sobre la situación de la Vivienda de Interés Social (VIS) en las ciudades de América Latina y analizar los instrumentos de gestión que inciden en su planeación, construcción y desempeño. Asimismo, debemos iniciar a cuestionar las bases de la planeación urbana bajo premisas utilitarias del pensamiento moderno y evolucionar a una ideología de enfoque eco-sistémico donde "[...] lo económico estará determinado por las relaciones complementarias y no utilitarias, con la naturaleza" (Mattioli, 2019, pág. 57).

Las ciudades de América Latina han presentado un aumento del 50\% de la población en los últimos 10 años y la mancha urbana se ha expandido proporcionalmente (Terraza et al., 2016). Actualmente en México, el 75\% de la población urbana se distribuye en ciudades medias (Terraza et al., 2016) y, algunas de ellas reportan tendencias de crecimiento por encima de la media nacional. Existe un contraste significativo en la relación de la tasa de crecimiento poblacional y la tasa de viviendas abandonadas. De los municipios con mayor tasa de crecimiento anual poblacional destaca Tlajomulco de Zúñiga, Jalisco con un 15.7\%. Este municipio sobresale de la media nacional por el contraste que presenta al tener la mayor tasa de crecimiento poblacional anual y al mismo tiempo pertenecer al grupo que registra mayor porcentaje de vivienda abandonada. Según el censo 2010 de Población y Vivienda, Tlajomulco casi duplicó su población en un periodo de cinco años y, según el Gobierno municipal de Tlajomulco de Zúñiga, el crecimiento de la población ya ha saturado la mayoría de las capacidades públicas y privadas para ofrecer servicios urbanos y municipales. Ahora los recursos naturales disponibles en el municipio tienen mayor presión y, en algunos casos, hay riesgos de agotamiento o pérdida por contaminación (Instituto de Información Estadística y Gegráfica de Jalisco, 2017). Con estas bases, este artículo aborda el municipio de Tlajomulco de Zúñiga, Jalisco como área de estudio.

\section{1 Área de estudio}

El objeto de estudio de este trabajo realizado entre 2017 y 2018 es el contexto urbano de la vivienda de interés social en el municipio de Tlajomulco de Zúñiga en Jalisco, México (Figura 1) y, se toma como unidad de análisis las colonias de Hacienda Santa Fe -construida entre 2002 y 2006- y

ACE, 14. (42) CC BY-ND 3.0 ES| UPC Barcelona, España | La insostenibilidad de los desarrollos de vivienda de interés social 
Chulavista - construida entre 2005 y 2008- por ser las de mayor población registrada con un total de 46,234 habitantes y 11,475 viviendas. De este universo, poco más del 12\% se encuentra en estado de abandono (IIEGJ, 2017).

Figura 1. Ubicación del municipio de Tlajomulco de Zúñiga, Jalisco, México

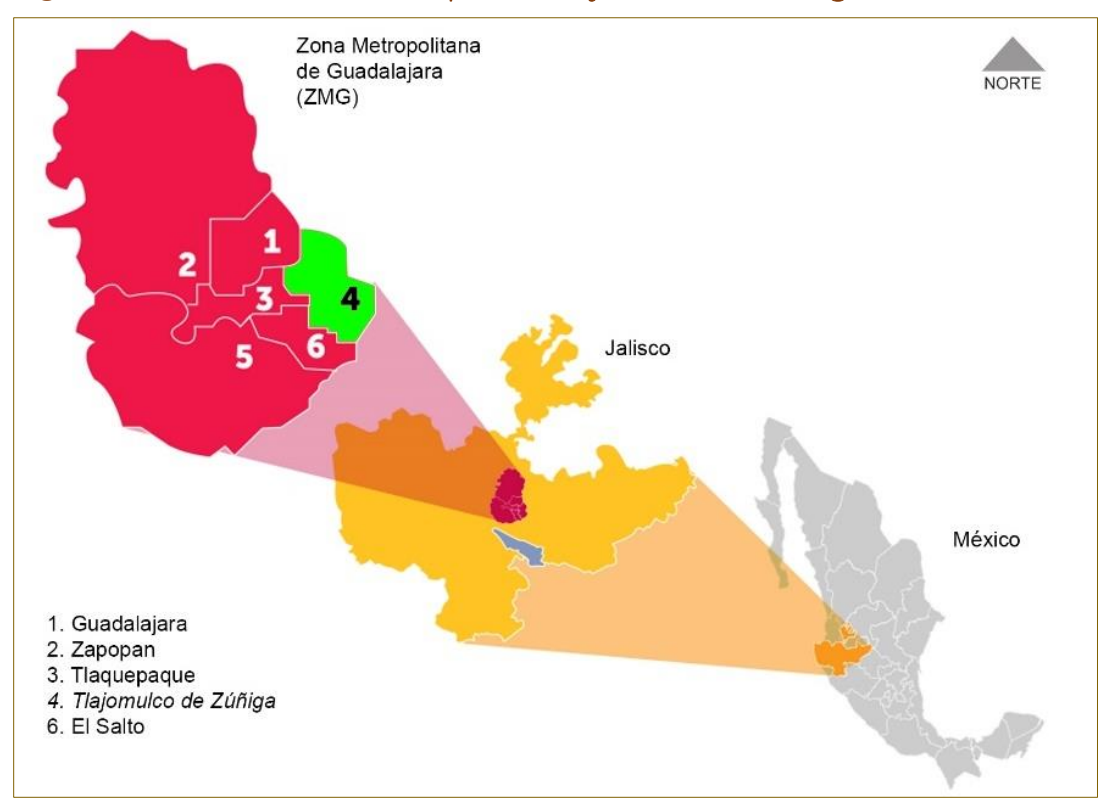

Fuente: http://jaliscocomovamos.org/donde-es-el-area-metropolitana-de-guadalajara

\section{Marco teórico de referencia}

\subsection{Reseña histórica de la producción de vivienda de interés social en México}

En México, según los registros históricos de población, el año de 1940 marca el antes y el después de la sociedad urbana - la reseña para esta investigación toma como punto de partida esta década-. El crecimiento poblacional que inició alrededor de esa década fue acompañado de necesidades de suelo y vivienda, esto abrió camino para la construcción de conjuntos habitacionales con presupuesto gubernamental asociado a la inversión privada. "Las primeras instituciones encargadas de la vivienda sólo tuvieron recursos para promover 53.622 viviendas sociales en alquiler, tales acciones -aunque importantes - resultaron insuficientes si tomamos en cuenta que en 1960 la cantidad de viviendas en el país era de 6,409,096. Durante esa década, el incremento del stock habitacional fue de 1,149,888, es decir: 18\%. Sólo 0.42\% fue promovida con el apoyo del Estado" (García Peralta, 2010, pág. 38). Una década más tarde surgió el Instituto Nacional de la Vivienda con el propósito de cubrir a los usuarios que no tuvieran acceso a la seguridad social (García Peralta, 2016), pero eran tiempos de crisis económica y la falta de empleo y la escasez de recursos obligó al Estado Mexicano a buscar formas de reactivación. Se pensó entonces en incentivar el ramo de la construcción y en 1962, se modificó la Ley General de Instituciones de Crédito y Organizaciones Auxiliares con el fin de incluir la banca privada en la producción de viviendas económicas (Esquivel et al., 2005). En este contexto, en 1963 se creó el Programa Financiero de Vivienda (PFV) para ofrecer la opción de tenencia propia a la población de nivel socioeconómico medio, bajo un esquema de financiamiento con capital privado (Cervantes et al., 2008). En 1972 se crearon el Instituto Nacional de Fomento a la Vivienda de los Trabajadores (INFONAVIT), y el Fondo para la Vivienda de los Trabajadores al Servicio del Estado

ACE, 14. (42) CC BY-ND 3.0 ES | UPC Barcelona, España | La insostenibilidad de los desarrollos de vivienda de interés social 4 en México: una aproximación desde el pensamiento de diseño. Caso de estudio: Tlajomulco de Zúñiga, Jalisco. DOI: http://dx.doi.org/10.5821/ace.14.42.8256 
(FOVISSSTE) que, conjuntamente el Fondo de Vivienda ligado a la banca (FOVI-Banca), produjeron el 77.3\% de las viviendas terminadas entre 1971 y 1976 (García Peralta, 2016).

La participación del Estado en la producción y financiamiento de las viviendas sociales disminuyó con la intervención del Banco Mundial mediante sus estrategias facilitadoras para que el sector privado diera mayor eficiencia a este mercado (Puebla, 2002). Para 1989, la política de vivienda había sido transformada al reducirse significativamente el presupuesto otorgado a los fondos de vivienda; así el INFONAVIT abandonó su condición de promotor para convertirse en facilitador (García Peralta, 2010). A partir de entonces el enfoque habitacional sería principalmente económico dejando de lado el tipo y la calidad de la vivienda ofertada (Esquivel et al., 2005). En 1993 entraron a escena otras entidades crediticias que cubrían a los sectores que no tenían acceso a créditos otorgados por facilitadores o intermediarios financieros. Estas entidades no bancarias fueron las Sociedades Financieras de Objeto Limitado (SOFOL). En 2006 se cambió la denominación de SOFOL a Sociedades Financieras de Objeto Múltiple (SOFOM). La diferencia con la banca es que estas sociedades no tienen la posibilidad de captar dinero del público, "su fondeo proviene de capital propio, bancos comerciales, emisiones en el mercado bursátil y la banca de desarrollo” (Hernández et al. 2009). Para el año 2001 un nuevo Organismo fue creado: el CONAFOVI (Comisión Nacional de Fomento a la Vivienda) bajo las bases del Plan Nacional de Desarrollo 2001-2006; teniendo como funciones: diseñar, dirigir y coordinar la política nacional de vivienda del Gobierno Federal que persigue garantizar la dotación de una "vivienda habitable" que impulse el desarrollo social y económico del país (Esquivel et al., 2005). En 2006, la CONAFOVI cambió al nombre de Comisión Nacional de Vivienda (CONAVI) y tiene como función principal asegurar que los mexicanos ejerzan su derecho a una vivienda adecuada (Comisión Nacional de Vivienda, 2019).

Preciso es mencionar que los casos de estudio de esta investigación fueron construidos en el periodo 2002-2008, posterior a la modificación de la CONAFOVI por CONAVI. ONU-Hábitat (2019), define una vivienda adecuada como aquella que satisface siete premisas: 1) Seguridad en la tenencia, 2) Disponibilidad de servicios, materiales, instalaciones e infraestructura, 3) Asequibilidad, 4) Habitabilidad, 5) Accesibilidad, 6) Ubicación y, 7) Adecuación cultural. Estas premisas se fundamentan en que una vivienda no debe concebirse solo como una unidad de infraestructura física sino como un espacio multidimensional pues no basta con buscar satisfacer la demanda de necesidades básicas en su reducto físico; se debe considerar que las necesidades humanas están interrelacionadas y no son categorías aisladas. "Una vivienda digna resulta fundamental para la supervivencia y para llevar una vida decente, en paz y con seguridad. Eso hace del derecho a la vivienda un derecho compuesto cuya vulneración acarrea la de otros derechos fundamentales [...]" (Pisarello, 2004, pág. 259). En México, la vivienda es un derecho constitucional y un indicador de bienestar; no obstante, el proceso actual de gestión para este tipo de proyectos ha facilitado la especulación inmobiliaria sobre el aseguramiento de las garantías individuales y el bienestar de los ocupantes. En el país se tienen registros de altas tasas de vivienda de interés social abandonada porque la infraestructura no asegura la satisfacción de las necesidades de habitabilidad y mucho menos una óptima calidad de vida sostenible en el tiempo. A nivel nacional existen algunos instrumentos diseñados para evaluar la calidad de la vivienda y su contexto urbano; tres de ellos servirán al presente trabajo para delimitar el marco de referencia: el índice de satisfacción residencial (ISR), el índice de sustentabilidad de la vivienda (ISV), y la evaluación cualitativa de la vivienda y su entorno (ECUVE).

\subsection{Instrumentos auxiliares para evaluar la calidad de la vivienda y su contexto urbano (habitabilidad)}

El primer instrumento es el índice de satisfacción residencial (ISR), el cual tiene base en la encuesta de satisfacción residencial realizada por la Sociedad Hipotecaria Federal (SHF) en 2006 y de la que se tiene registro hasta 2014. El índice tiene el objetivo de evaluar la calidad de la vivienda y la del

ACE, 14. (42) CC BY-ND 3.0 ES | UPC Barcelona, España | La insostenibilidad de los desarrollos de vivienda de interés social 5 en México: una aproximación desde el pensamiento de diseño. Caso de estudio: Tlajomulco de Zúñiga, Jalisco. DOI: http://dx.doi.org/10.5821/ace.14.42.8256

Calderón, C. et al. 
conjunto habitacional donde se encuentra. Sus componentes son tres: el índice de satisfacción de la vivienda, el índice de satisfacción del desarrollo urbano y el índice de satisfacción financiera (Sociedad Hipotecaria Federal, 2015). En la tabla 1 se enuncian los parámetros contenidos en cada índice para realizar la evaluación.

Tabla 1. Componentes del Índice de satisfacción residencial (ISR)

\begin{tabular}{|c|c|}
\hline Índice & Parámetros (componentes) \\
\hline \multirow[t]{4}{*}{ Índice de satisfacción de la vivienda } & Características físicas de la construcción \\
\hline & Características funcionales y espaciales \\
\hline & Flexibilidad para adaptación y transformaciones \\
\hline & Características ambientales \\
\hline \multirow{6}{*}{$\begin{array}{l}\text { Índice de satisfacción del conjunto } \\
\text { habitacional y de la ciudad }\end{array}$} & Localización \\
\hline & Características del conjunto habitacional \\
\hline & Urbanización y servicios \\
\hline & Percepción del conjunto \\
\hline & Equipamiento social y comunitario \\
\hline & Percepción de la ciudad \\
\hline \multirow[t]{3}{*}{ Índice de satisfacción financiera } & Características del crédito \\
\hline & Tiempos de respuesta \\
\hline & Características del servicio \\
\hline
\end{tabular}

Fuente: Elaboración propia a partir del Estado Actual de la Vivienda en México (SHF, 2015). Nota: El ISR es evaluado con base en la siguiente escala: $5 \leq$ ISR < 6: Nada satisfactorio; $6 \leq$ ISR $<7$ : Poco satisfactorio; $7 \leq$ ISR $<8$ : Satisfactorio bajo; $8 \leq$ ISR < 9: Satisfactorio medio; $9 \leq$ ISR < 10: Satisfactorio alto; ISR = 10: Muy satisfactorio.

Entre las conclusiones más relevantes sobre la calidad de la vivienda y su contexto urbano a partir de la encuesta de satisfacción residencial (ESR) reportada en el EAVM 2015 se tienen las siguientes:

- Históricamente el promedio del índice de satisfacción con la vivienda ha oscilado entre $6 \leq$ ISR < 7 indicando que es poco satisfactorio, así también el índice de satisfacción del conjunto habitacional y de la ciudad (SHF, 2015).

- Los conjuntos habitacionales mejor evaluados (satisfactorio alto) pertenecen a la tipología residencial y media, mientras que los peor evaluados (nada satisfactorio) pertenecen a la tipología de vivienda de interés social (SHF, 2015).

- "Los conjuntos financiados para construcción por SHF tienen mejores calificaciones que el resto de los conjuntos. Los desarrollos certificados resultaron peor calificados que el resto [...]" (SHF, 2015, pág. 52).

En términos más específicos, Martínez e Ibarra (2017) realizaron un análisis para conocer los determinantes de la satisfacción residencial en México a partir de datos obtenidos en la ESR 2013 donde se agrupan 512 conjuntos habitacionales. En el estudio se concluye que la satisfacción residencial está determinada en gran medida por el tipo de tenencia de la vivienda; quienes son dueños de la vivienda, así sostengan una hipoteca, tienden a sentirse satisfechos pues ello les representa seguridad y libertad. Por otro lado, existen otras variables que, aunque no son determinantes, tienen una relación positiva y estadísticamente significativa con la satisfacción residencial. Estas son: pago de cuotas de mantenimiento, contar con un mayor número de cajones de estacionamiento por vivienda y, hacer uso de tecnologías de ahorro de agua y energía. Por otro lado, se encontró que los factores que tienden a disminuir la satisfacción residencial son: mala convivencia con vecinos, percepción de riesgo por mala ubicación y la antigüedad de la infraestructura. Asimismo, sostiene que "[...] la sustentabilidad de la vivienda está aparejada con la satisfacción residencial en los complejos habitacionales mexicanos” (Martínez e Ibarra, 2017).

El segundo instrumento es el Índice de Sustentabilidad de la Vivienda (ISV). Fue diseñado para evaluar el desempeño ambiental, económico y social de la vivienda de interés social y su contexto urbano en México (Centro Mario Molina, 2012). La diferencia fundamental con el índice anterior es su enfoque

ACE, 14. (42) CC BY-ND 3.0 ES | UPC Barcelona, España | La insostenibilidad de los desarrollos de vivienda de interés social 
sistémico. Sus componentes son: el índice ambiental, el índice económico y el índice social. La tabla 2 muestra los indicadores que estructuran a cada índice.

Tabla 2. Componentes del Índice de Sustentabilidad de la Vivienda (ISV)

\begin{tabular}{|c|c|c|}
\hline Índice & \multicolumn{2}{|c|}{ Parámetros (componentes) } \\
\hline \multirow{5}{*}{$\begin{array}{l}\text { Índice } \\
\text { ambiental }\end{array}$} & Uso de suelo & Cambio climático \\
\hline & Abastecimiento de agua & Toxicidad humana \\
\hline & Abastecimiento de energía & Acidificación \\
\hline & Eco-toxicidad & Eutrofización \\
\hline & Formación de oxidantes fotoquímicos & Manejo y disposición de residuos sólidos \\
\hline \multirow{3}{*}{$\begin{array}{l}\text { Índice } \\
\text { económico }\end{array}$} & Variación en el gasto familiar & Gastos de transporte como porcentaje del ingreso \\
\hline & $\begin{array}{l}\text { Ahorros por la implementación de eco- } \\
\text { tecnologías }\end{array}$ & Formación de patrimonio \\
\hline & $\begin{array}{l}\text { Gastos de vivienda como porcentaje del } \\
\text { ingreso }\end{array}$ & Plusvalía \\
\hline \multirow{7}{*}{$\begin{array}{l}\text { Índice } \\
\text { social }\end{array}$} & Variación de los espacios & Organización de los vecinos \\
\hline & Adecuación de los espacios & Espacios públicos \\
\hline & $\begin{array}{l}\text { Influencia del tamaño de los espacios en } \\
\text { las relaciones familiares }\end{array}$ & Convivencia social \\
\hline & Calidad de los materiales & Administración vecinal \\
\hline & Índice de hacinamiento & Índice de rezago social \\
\hline & Variación en el entorno & Variación en los servicios de transporte \\
\hline & Suficiencia de equipamiento urbano & Tiempo de transporte \\
\hline
\end{tabular}

Fuente: Centro Mario Molina, 2012. Nota: El ISV es evaluado en una escala de 0 a 100.

En 2012, con el cálculo del ISV, los resultados arrojaron un rango de 41 a 48 puntos, esto quiere decir que la tendencia es de una sustentabilidad media-baja (Centro Mario Molina, 2012). Los hallazgos del ISV más relevantes para efectos del presente artículo son:

- El nivel de desempeño encontrado "es propio de una vivienda que cumple con la normatividad mínima a nivel nacional, caracterizada por patrones insostenibles de ocupación del suelo, un alto consumo de energéticos contaminantes y un pobre aprovechamiento de los recursos hídricos" (Centro Mario Molina, 2012).

- Las familias que ocupan esta infraestructura destinan en promedio el 39\% de los ingresos para vivienda y transporte. Casi una cuarta parte de éstos gasta más del $20 \%$ de su ingreso sólo en transporte (Centro Mario Molina, 2012).

- Se puede decir que las poblaciones de estas viviendas están lejos del rezago social pues cuentan con acceso a servicios básicos de educación, salud y vivienda digna; no obstante, sólo un porcentaje mínimo de la población identifica casas de cultura o programas de desarrollo comunitario. Esto los empuja a tener mayores desplazamientos, gastar más recursos económicos y ocupar más horas de su día para tener accesos a los centros urbanos (Centro Mario Molina, 2012).

- Los resultados enunciados son generales y cuando se llevan a escalas regionales los índices presentan variaciones significativas lo que indica la pertinencia de analizar el desempeño en cada ciudad (Centro Mario Molina, 2012).

Para cerrar esta sección se presenta el tercer instrumento: la Evaluación Cualitativa de la Vivienda y su Entorno (ECUVE). Es realizada por el Instituto del Fondo Nacional de la Vivienda para los Trabajadores (INFONAVIT) a través del Centro de Investigación para el Desarrollo Sostenible (CIDS) anualmente desde 2011. La ECUVE valora el impacto que tiene la infraestructura de vivienda en la calidad de vida de los acreditados al Instituto. A diferencia del ISR, esta evaluación no sólo califica el grado de satisfacción con la vivienda, sino que además estima las cualidades del contexto urbano

ACE, 14. (42) CC BY-ND 3.0 ES | UPC Barcelona, España | La insostenibilidad de los desarrollos de vivienda de interés social 7 en México: una aproximación desde el pensamiento de diseño. Caso de estudio: Tlajomulco de Zúñiga, Jalisco. DOI: http://dx.doi.org/10.5821/ace.14.42.8256 
donde esta se ubique (Sociedad Hipotecaria Federal, 2018). Los atributos que califica son: superficie habitable, transporte público, ubicación, mercados, competitividad económica, servicios de voz y datos, eficiencia energética, ahorro de agua, calidad comunitaria, calidad de la vivienda y la calidad del equipamiento urbano como son: escuelas, hospitales y parques. La escala que utiliza es de 0 a 180 y la puntuación depende de la accesibilidad a los servicios y de su buen funcionamiento (Centro de Investigación para el Desarrollo Sostenible, 2019). El promedio de los últimos cinco años a nivel nacional es: 114.62 (SHF, 2018).

La problemática exige el replanteamiento de la participación del Estado en la planeación espacial para regular la intervención del sector inmobiliario en la producción de la vivienda y del espacio urbano. Considerando a Lefebvre (2013), a propósito de la ciudad concebida como la expresión de la confluencia de flujos socio-territoriales en un tiempo determinado, en este trabajo se plantea que el abordaje de la producción del espacio urbano requiere de nuevas metodologías de análisis, como lo son: 1) El método de pensamiento de diseño, el cual ofrece una plataforma de diálogo con los usuarios de la VIS ${ }^{1}$ y, 2) La metodología de gestión del ciclo del proyecto, que comprende el desarrollo del proyecto arquitectónico y urbano desde la planeación hasta la producción del espacio edificado y la evaluación de su desempeño.

\section{Marco metodológico}

La metodología se divide en dos apartados: El primero con fundamentación teórica y, el segundo a través del análisis de datos empíricos. La parte primera consiste en el análisis del ciclo de gestión de producción de la VIS donde se identificaron instrumentos y procesos de planeación y construcción. La segunda parte, es una aproximación empírica a la problemática a través del pensamiento de diseño. Las bases epistemológicas coinciden con el planteamiento de Elinbaum (2018): abordar el planeamiento urbano como una construcción social que integra instrumentos y contexto social. La Figura 2 esquematiza el desarrollo de este trabajo.

Figura 2. Marco metodológico

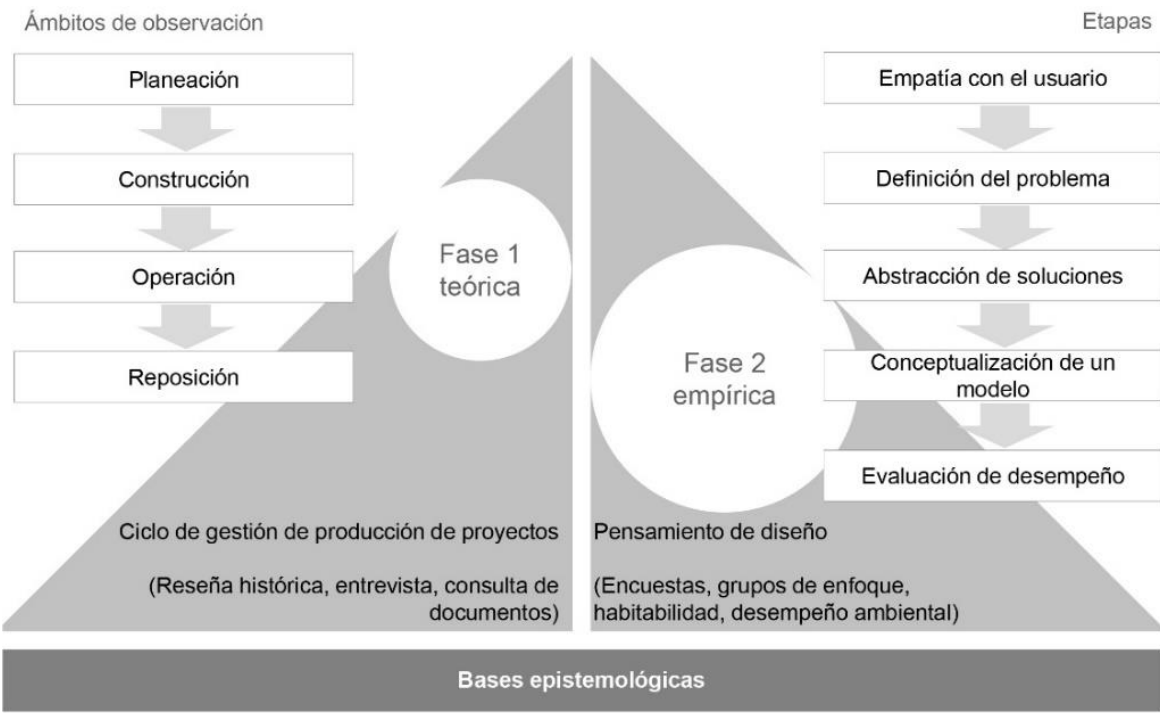

Fuente: Elaboración propia.

1 Vivienda de Interés Social (VIS)

ACE, 14. (42) CC BY-ND 3.0 ES | UPC Barcelona, España | La insostenibilidad de los desarrollos de vivienda de interés social en México: una aproximación desde el pensamiento de diseño. Caso de estudio: Tlajomulco de Zúñiga, Jalisco. DOI: http://dx.doi.org/10.5821/ace.14.42.8256 


\subsection{El ciclo de gestión de producción de proyectos}

Se utiliza este marco para identificar los determinantes del éxito o fracaso de un proyecto con base en la revisión de los procesos de gestión. Para efectos de este trabajo se define un proyecto como el conjunto de procesos, actividades y técnicas ejecutados para la creación de un bien o un servicio que satisfaga necesidades concretas. Sin importar las diferencias de escala y naturaleza de los proyectos, existen procesos comunes en su desarrollo, al conjunto de estos procesos comunes se le denomina ciclo de proyecto (Terrazas, 2009). Esta investigación ha adoptado la estructura del ciclo de proyectos para mapear los procesos involucrados en la producción de la VIS. El ciclo de proyecto para este tipo de infraestructura se ha acotado a cuatro ámbitos de observación: planeación, construcción, operación y reposición.

Ámbito de observación 1: Planeación.

En este apartado se reconocen los instrumentos rectores que regulan las condiciones físicas y jurídicas del suelo urbanizable y los instrumentos que establecen las pautas de diseño generales para la elaboración de proyectos de vivienda de interés social. El apoyo de la investigación es una entrevista al director general de ordenamiento territorial del municipio de Tlajomulco de Zúñiga para conocer los procesos de planeación urbana que inciden en el desarrollo de la VIS.

Ámbito de observación 2: Construcción.

El objetivo de este apartado es identificar los instrumentos que regulan los procesos constructivos de los conjuntos habitacionales, así como identificar los instrumentos de control para asegurar que los planes de proyecto se ejecuten como fueron concebidos y autorizados.

Ámbito de observación 3: Operación.

Con este ámbito de observación se busca registrar y describir los instrumentos de monitoreo y control sobre la calidad y el nivel de satisfacción de los usuarios para con la vivienda y su entorno.

Ámbito de observación 4: Reposición.

Este apartado tiene el objetivo de describir los procesos existentes para revitalizar o reponer la vivienda de interés social abandonada o en deterioro.

\subsection{El pensamiento de diseño}

El pensamiento de diseño es un modelo multidisciplinario de trabajo. El término fue utilizado por Tom Kelley en el texto The Art of Innovation publicado en 2001, donde se manifiesta la conjunción del pensamiento empresarial con el trabajo de creativos para otorgar soluciones a problemáticas dentro del área del diseño. No obstante, el término ha sido permeado a otros campos de conocimiento a través del discurso de Charles L. Owen dado en The International Conference on Design Research and Education for the Future. En este discurso se presenta este modelo de pensamiento como una herramienta para atender necesidades específicas o difusas y solucionar problemas complejos. Según Torres (2017), INSITUM -empresa dedicada a la investigación estratégica- describe que son tres los ejes de práctica del pensamiento de diseño: "1) Las ciencias sociales son la fuente de información intelectual y de las técnicas intuitivas necesarias para llegar a tener la visión del consumidor; 2) El pensamiento estratégico de negocio es el instrumento que permite la innovación de su estructura y sus propias prácticas y; 3) el diseño es el instrumento epistemológico integrador del proceso" (Esqueda et al., 2017). El éxito de este modelo se ha probado en la aplicación de proyectos de innovación social y en la aplicación en proyectos donde además de considerar las necesidades de los usuarios en un producto final, se debe considerar la experiencia que el usuario tenga a lo largo del ciclo de producción del objeto y su experiencia durante el consumo. Esta metodología se ha utilizado para facilitar la participación ciudadana en procesos de creación de

ACE, 14. (42) CC BY-ND 3.0 ES | UPC Barcelona, España | La insostenibilidad de los desarrollos de vivienda de interés social 9 en México: una aproximación desde el pensamiento de diseño. Caso de estudio: Tlajomulco de Zúñiga, Jalisco. DOI http://dx.doi.org/10.5821/ace.14.42.8256

Calderón, C. et al. 
políticas públicas o para permear y concientizar sobre los efectos del cambio climático a distintos estratos de la población. De acuerdo con Brown y Wyatt (2010), este método se compone de cinco etapas: 1) Empatía con el usuario, 2) Definición del problema, 3) Abstracción de soluciones, 4) Conceptualización de un modelo y, 5) Evaluación del desempeño.

Etapa 1: Empatía con el usuario.

En la primera etapa se extrae información de los usuarios para conocer las condiciones actuales de habitabilidad ${ }^{2}$ con respecto a la vivienda que ocupan. Con ese objetivo se diseñó una encuesta de trece ítems aplicado a una muestra de 339 viviendas. La encuesta diseñada consta de dos apartados: el primero de once preguntas para evaluación en escala de Likert y el segundo se trata de dos preguntas abiertas. Los primeros once ítems se diseñaron para evaluar cualitativamente la habitabilidad de la vivienda y el conjunto habitacional mientras que las preguntas abiertas se concentraron en obtener datos específicos sobre motivaciones y aspiraciones de la población con respecto al lugar habitable. El cálculo de la muestra segmentó el área de estudio en cuatro regiones tomando como fronteras elementos físicos como parques y avenidas, se utilizó el esquema de muestreo estratificado al azar y se le otorgó un peso (W) a cada segmento de acuerdo a la proporción estimada de las viviendas totales por sección entre la población total (Tabla 3).

Tabla 3. Tamaño de la muestra para Hacienda de Santa Fe en Tlajomulco de Zúñiga, Jalisco.

\begin{tabular}{|c|c|c|c|}
\hline Estrato & \# de viviendas & W (peso) & n (tamaño de muestra) \\
\hline 1 & 3,298 & 0.29 & 59 \\
\hline 2 & 1,948 & 0.17 & 88 \\
\hline 3 & 2,978 & 0.26 & 97 \\
\hline 4 & 3,251 & 0.28 & 339 \\
\hline n (tamaño de la muestra) & 11,475 & 1.00 & 38 \\
\hline
\end{tabular}

Fuente: Elaboración propia.

El tamaño de muestra $(n)$ se calculó con la proporción $(p=0.5)$, un nivel de confianza del 95\% ( $z=1.96)$ y se consideró un error del 10\% de acuerdo a la siguiente ecuación.

$$
n_{2}=\frac{z_{\alpha}^{2}[p(1-p)] N}{z_{\alpha}^{2}[p(1-p)]+(N-1) c_{p}^{2}}
$$

n: tamaño de la muestra; z: nivel de confianza (95\%); p: proporción; N: tamaño de la población; c: error admitido (10\%)

En la Tabla 4 se muestra el código utilizado para la validación de la encuesta y se definen los valores de referencia con base en la escala de Likert ${ }^{3}$. La encuesta fue validada con un coeficiente alfa de Cronbach de 0.741 de acuerdo con el análisis de fiabilidad que se realizó con ayuda del paquete estadístico SPSS Inc. ${ }^{\circledR}$

Etapas 2 y 3: Definición del problema y abstracción de soluciones.

Se realizó un diagnóstico a través de grupos de enfoque en el área de estudio utilizando de base la metodología de la investigación-acción participativa. El objetivo fue comprender las aspiraciones, necesidades y satisfactores de la población estudio. El instrumento empleado (Tabla 5) se diseñó con base en la teoría de la jerarquía de las necesidades, la cual expone que las necesidades humanas se

\footnotetext{
2 Habitabilidad: "Atributo de los espacios construidos de satisfacer las necesidades objetivas y subjetivas de los individuos y grupos que las ocupan” (Castro et al., 2001).

${ }^{3}$ La escala de Likert es una escala de actitud. "El modelo metodológico que sirve de base a este procedimiento es un modelo monótono aditivo, en el que los mismos sujetos se gradúan o se escalan ellos mismos respecto al objeto de actitud" (Alaminos \& Castejón, 2006)
} 
pueden priorizar, siendo las fisiológicas las de primer orden (Maslow, 2012). Según la pirámide de Maslow, los grupos de necesidades en orden prioritario son: fisiológicas, de seguridad, de afiliación, de reconocimiento y por último de auto-realización. En desarrollo a escala humana se expone que las personas somos seres con múltiples necesidades que se relacionan e interactúan entre sí y, se hace hincapié entre la diferencia conceptual de necesidad y satisfactor. Para estudiar las necesidades humanas, en desarrollo a escala humana se establecieron dos categorías: axiológicas y existenciales. En las axiológicas se agrupa lo referente a ser, tener, hacer y estar; mientras que en las existenciales se concentran las necesidades de subsistencia, protección, afecto, entendimiento, participación, ocio, creación, identidad y libertad (Max-Neef et al., 2010).

Tabla 4. Código para validación de encuesta con base de escala de Likert

\begin{tabular}{|l|l|l|l|l|l|}
\hline \multicolumn{1}{|c|}{ Palabra clave del ítem } & \multicolumn{3}{c|}{ Escala de respuestas } \\
\hline & \multicolumn{1}{|c|}{1} & \multicolumn{1}{c|}{3} & \multicolumn{1}{c|}{4} & \multicolumn{1}{c|}{5} \\
\hline Confort espacial & Muy malo & Malo & Regular & Bueno & Muy bueno \\
\hline Confort térmico invierno & Muy malo & Malo & Regular & Bueno & Muy bueno \\
\hline Confort térmico verano & Muy malo & Malo & Regular & Bueno & Muy bueno \\
\hline Confort acústico & Muy malo & Malo & Regular & Bueno & Muy bueno \\
\hline Confort conjunto habitacional & Muy malo & Malo & Regular & Bueno & Muy bueno \\
\hline Participación social & Nula & Pobre & Regular & Activa & Muy activa \\
\hline Visión a largo plazo & Mucho peor & Peor & Sin cambio & Mejor & Mucho mejor \\
\hline Uso áreas verdes & Nunca & Ocasional & Regular & Frecuente & Muy frecuente \\
\hline Alumbrado & Muy malo & Malo & Suficiente & Bueno & Muy bueno \\
\hline Seguridad & Muy malo & Malo & Suficiente & Bueno & Muy bueno \\
\hline Preocupación medio ambiente & No & Poco & Indiferente & Preocupado & Muy \\
\hline
\end{tabular}

Fuente: Elaboración propia.

Tabla 5. Niveles de habitabilidad en función de las necesidades y sus satisfactores

\begin{tabular}{|c|c|c|c|c|}
\hline $\begin{array}{c}\text { Necesidad } \\
\text { expresada }\end{array}$ & $\begin{array}{c}\text { Satisfactor } \\
\text { identificado }\end{array}$ & $\begin{array}{c}\text { Necesidad } \\
\text { humana }\end{array}$ & $\begin{array}{c}\text { Correspondencia necesidad } \\
\text { axiológica - existencial }\end{array}$ & $\begin{array}{c}\text { Nivel de } \\
\text { habitabilidad }\end{array}$ \\
\hline & & & & \\
\hline
\end{tabular}

Fuente: Elaboración propia. Nota: Deberá llenarse la tabla incluyendo tantas filas como necesidades sean expresadas.

Posteriormente se realizó una lluvia de ideas para conceptualizar propuestas de solución a las necesidades no satisfechas. Las dinámicas se realizaron con dos tipos de grupo y tres iteraciones por tipo. Los grupos se clasificaron de la siguiente manera: a) Grupo tipo 1: Adultos de 18 a 60 años de edad, y b) Grupo tipo 2: Adultos mayores de 60 años y personas con capacidades diferentes. El instrumento diseñado para concentrar la información extraída es una matriz de problemas y soluciones en el área de estudio (Tabla 6).

Tabla 6. Matriz de problemas y soluciones en el área de estudio

\begin{tabular}{|l|l|}
\hline Descriptor & \\
\hline Problema & \\
\hline Causa & \\
\hline Impacto & \\
\hline Solución & \\
\hline
\end{tabular}

Fuente: Elaboración propia. Nota: Deberá llenarse la tabla incluyendo tantas filas como problemáticas prioritarias se establezcan.

ACE, 14. (42) CC BY-ND 3.0 ES | UPC Barcelona, España | La insostenibilidad de los desarrollos de vivienda de interés social 
Etapa 4: Conceptualización de un modelo.

La teoría indica que se debe modelar un prototipo con las necesidades expresadas por los usuarios. Para efectos de esta investigación, el prototipo considerado fue el estado actual de la vivienda de interés social en el área de estudio con el único fin de evaluar su desempeño.

Etapa 5: Evaluación del desempeño.

Para evaluar el desempeño nos referimos a la calidad ambiental. La evaluación se realizó por medio de un análisis exploratorio de datos empíricos con base en criterios establecidos en la herramienta CASBEE-UD ${ }^{4}$. Este instrumento considera tres categorías para evaluar la calidad ambiental: 1) Calidad del medio ambiente natural, 2) Calidad de los servicios urbanos y, 3) Contribución a la comunidad. Es preciso señalar que, aunque estas categorías se tomaron de la herramienta CASBEE-UD, los valores de referencia fueron ajustados con base en la normatividad local ${ }^{5}$ y se extrajeron los requerimientos obligatorios con los que se debe cumplir para que una zona urbana pueda considerarse sustentable . $^{6}$ En la Tabla 7 se muestra el condensado de los criterios analizados.

Tabla 7. Criterios ponderados para la evaluación de la calidad ambiental (Q)

\begin{tabular}{|l|}
\hline \multicolumn{1}{|c|}{ Criterios } \\
\hline Q1 Calidad del medio ambiente natural (microclimas y ecosistemas) \\
\hline 1.1 Evaluación de la conservación de microclimas en áreas peatonales en verano \\
\hline 1.3 Importancia y conservación del medio acuático \\
\hline 1.4 Conservación y creación de hábitat \\
\hline 1.5 Otras consideraciones dentro del área de estudio \\
\hline Q2 Calidad de los servicios urbanos en el área de estudio \\
\hline 2.1 Desempeño de los sistemas de abastecimiento y tratamiento (agua, alcantarillado y energía) \\
\hline 2.2 Desempeño de los sistemas de información \\
\hline 2.3 Desempeño de los sistemas de transporte \\
\hline 2.4 Prevención de desastres y delincuencia \\
\hline 2.5 Confort en la vida diaria \\
\hline 2.6 Evaluación del diseño universal \\
\hline Q3 Contribución a la comunidad local \\
\hline 3.1 Empleo de los recursos locales \\
\hline 3.2 Contribución a la formación de infraestructura social \\
\hline 3.3 Consideraciones para construir una buena comunidad \\
\hline 3.4 Imagen urbana \\
\hline
\end{tabular}

Fuente: Elaboración propia a partir de CASBBE-UD (Institute for Building Environment and Energy Conservation, 2018).

Calidad del medio ambiente natural.

Para los efectos de esta investigación, la calidad del medio ambiente natural está determinada en función de la calidad de los servicios ambientales que el medio natural dentro del ambiente construido pueda otorgar. Los elementos que se tomaron en cuenta para este análisis fueron: 1)

\footnotetext{
${ }^{4}$ Comprehensive Assessment System for Building Environmental Efficiency-Urban Development (CASBEE-UD) (Institute for Building Environment and Energy Conservation, 2018).

${ }^{5}$ Los valores de referencia para el uso de la herramienta CASBEE - UD fueron extraídos de la Norma para la Edificación y Hábitat Sustentable NMX-AA-164-2013. Las bases de esta NMX están contenidas en la Ley General de Equilibrio Ecológico y Protección al Ambiente, la Ley de Aguas Nacionales, la Ley General de Asentamientos Humanos, Ley General para la Prevención y Gestión de Los Residuos, y en la Ley de Aprovechamiento Sustentable de la Energía. El objetivo de la Norma Mexicana es establecer los requerimientos mínimos para la construcción de hábitat sustentable mediante una lista de verificación (NMX-AA-164-2013, 2013).

${ }^{6}$ Para efectos de este trabajo el término sustentable y sostenible se utilizan como sinónimos.
} 
Coeficiente de área verde ${ }^{7}$, donde el valor de referencia para el óptimo nivel de bienestar es superior al 65\% de área verde respecto a la superficie total del predio, 2) Preservación, restauración y mejoramiento de las condiciones topográficas del lugar, 3) Preservación y conservación de los ciclos naturales del agua por reposición de aguas subterráneas dentro del área de estudio, 4) Creación de redes eco-sistémicas -formación de corredores naturales como un parque lineal o manejo de ecotonos ${ }^{8}$ - 5) Elementos adicionales para garantizar la buena calidad del aire, regulación del ruido y vibraciones tales como: formación de cortinas de árboles.

Calidad de los servicios urbanos.

Para la evaluación de los servicios urbanos se incluyeron los siguientes elementos: 1) Factibilidad de abastecimiento (agua, alcantarillado y energía), 2) Dotación de los servicios y funcionamiento de las redes, 3) Preparación de los servicios en caso de siniestros, 4) Conectividad del sistema de transporte público, 5) Movilidad peatonal y vehículos no motorizados, 4) Sistemas de prevención de desastres y delincuencia y, 5) Conectividad con servicios públicos como escuelas y hospitales.

\section{Contribución a la comunidad.}

Se llevó a cabo un reconocimiento en sitio de la infraestructura social que por su uso contribuyera a la formación de puntos de encuentro como fomento a la vitalidad de la comunidad, la comunicación y la participación social. Se consideraron como infraestructura social todas aquellas áreas verdes existentes, plazas, parques o jardines que sirvan como espacios de esparcimiento y recreación, se consideraron también todas las obras y servicios considerados como infraestructura y equipamiento urbano.

\section{Resultados}

\subsection{Resultados con base en el marco del ciclo de gestión de producción de proyectos}

La extracción de datos se llevó a cabo a través de la consulta de documentos oficiales: planos, memorias de cálculo, dictámenes de impacto ambiental y resolutivos de autorización de proyecto; documentación proporcionada por la Dirección Desarrollo Urbano y Obras Públicas Municipales. Asimismo, se consultaron los siguientes documentos: Gaceta Municipal 2016, Normas Técnicas Complementarias para diseño arquitectónico y Normas Técnicas a las que hiciera referencia el reglamento de construcciones según el criterio analizado, Ley de Desarrollo Urbano del Estado de Jalisco 2013, Ley de Vivienda del Estado de Jalisco, Ley General del Equilibrio Ecológico y Protección al Ambiente 2012, plan parcial de desarrollo urbano de Tlajomulco de Zúñiga, Jal. y el Ordenamiento de Ecología y Medio Ambiente para el municipio de Tlajomulco.

Con base en la investigación documental descrita se identificó el ciclo de gestión de proyectos de vivienda de interés social en México como un sistema abierto donde se observaron los ámbitos siguientes: planeación, construcción, operación y reposición (Figura 3).

\footnotetext{
${ }^{7}$ Coeficiente de Área Verde (CAV): "Es el lineamiento urbanístico que determina la superficie de un predio que deberá quedar libre de techo, pavimento, sótano o de cualquier material impermeable y que únicamente sea destinada para jardín, área verde o arborización, con el fin de cumplir con la absorción del suelo. Dicho coeficiente, se obtiene de dividir la superficie de área verde entre la superficie total del lote o predio". Reglamento de Zonificación y Uso de Suelo del Municipio.

${ }^{8}$ En este trabajo se utiliza el término ecotono de igual manera que el término ecotono urbano para referir a un área transicional entre el medio ambiente natural y el medio ambiente construido por el hombre.
}

ACE, 14. (42) CC BY-ND 3.0 ES| UPC Barcelona, España | La insostenibilidad de los desarrollos de vivienda de interés social 
Figura 3. Ciclo de gestión de proyectos de VIS en México (2001-2018)

\section{Enfoque: Vivienda de interés social} Base: Economía del desarrollo

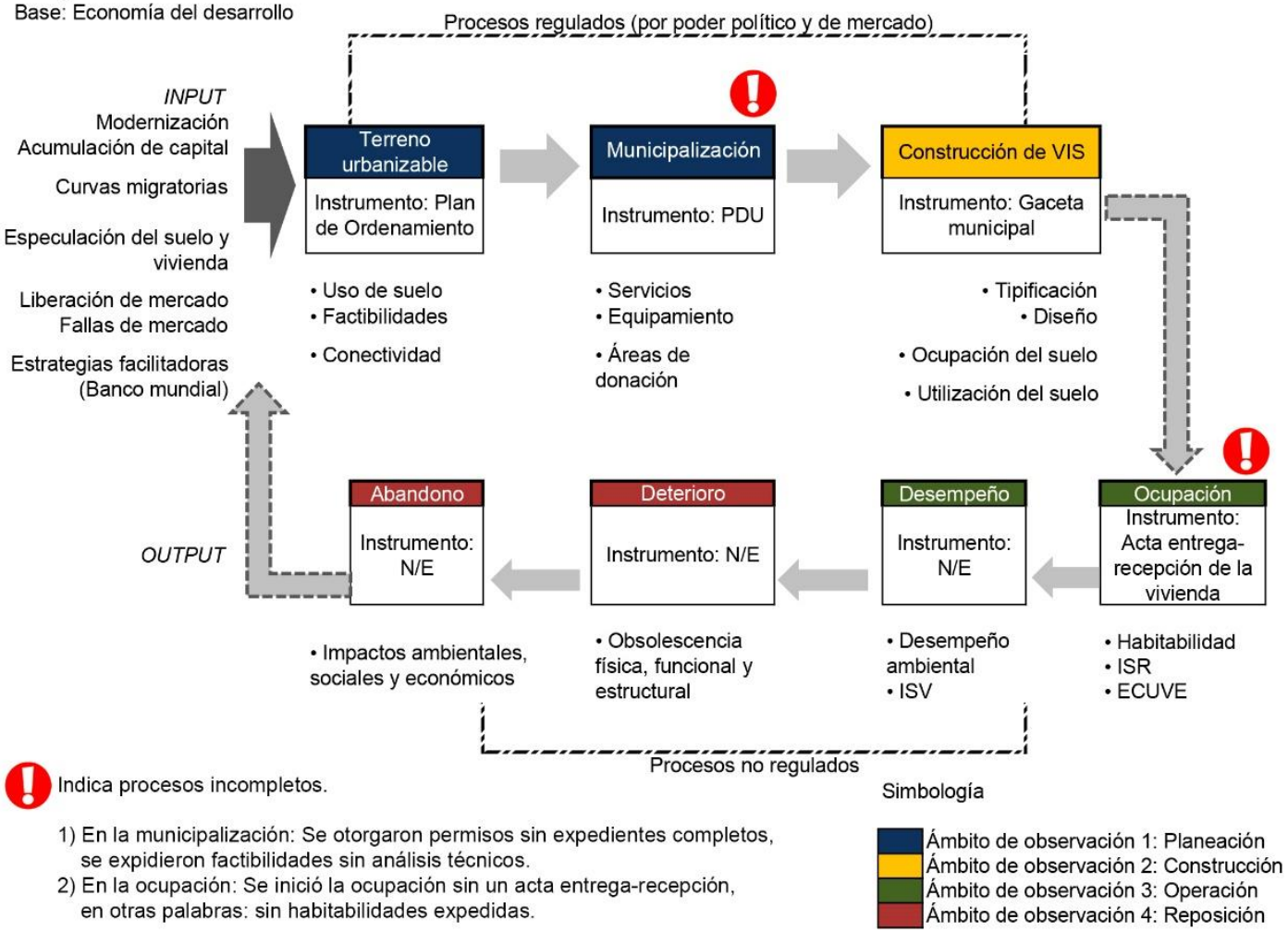

Fuente: Elaboración propia. Plan de Desarrollo Urbano (PDU), No especifica (N/E), Índice de sustentabilidad de la vivienda (ISV), Índice de satisfacción residencial (ISR), Evaluación cualitativa de la vivienda y su entorno (ECUVE).

Ámbito de observación 1: Planeación.

Esta etapa está moldeada por dos instrumentos rectores: el Plan de Ordenamiento Territorial y el Plan de Desarrollo Urbano. Estos dos instrumentos regulan las condiciones físicas y jurídicas del suelo urbanizable: marcan los usos de suelo, las pautas de diseño generales, el nivel de equipamiento y los servicios públicos a los que los usuarios de las viviendas deberían tener acceso. El siguiente párrafo es un extracto de la entrevista que para efectos de esta investigación se llevó a cabo con el director general de ordenamiento territorial del municipio de Tlajomulco de Zúñiga.

Históricamente la asignación de uso de suelo ha estado ligada al crecimiento de zonas ya existentes. Normalmente se detona algún fraccionamiento y entonces alrededor se empiezan a detonar otros: es la tendencia que han seguido los planes de desarrollo urbano. [...] Para definir los parámetros de planeación urbana para la vivienda no se hace mucho análisis ahorita porque la verdad no hay muchos que se animen. [...] Los problemas de vivienda abandonada muchos se deben a la falta de transporte, falta de lugares de trabajo y a obras inconclusas abandonadas incluso por el urbanizador. [...] Las factibilidades pueden hacerse de manera un poco rancherona, al feeling del director en turno [...], entonces más o menos se sabe por dónde hay agua y por donde no hay agua, entonces más o menos sabemos por dónde se puede fomentar vivienda y por donde no. [...] En cuanto a los actores principales: por un lado, está el gobierno municipal, que es quien autoriza al final de cuentas; por otro lado, están los urbanizadores, que son los que hacen el negocio de vender los lotes y las casas; los urbanizadores compran la tierra a ejidatarios, a particulares, etcétera. Y allí es donde empieza el circulo vicioso porque conforme uno se va acercando a la Zona Metropolitana de Guadalajara (ZMG) los terrenos se van haciendo más caros y ya no pueden entrar dentro de los costos y presupuestos

ACE, 14. (42) CC BY-ND 3.0 ES| UPC Barcelona, España | La insostenibilidad de los desarrollos de vivienda de interés social 
de los fraccionamientos de interés social, entonces tienen que hacerse más lejos. Entonces la presión hacia los gobiernos municipales es: oye sabes que, autorízame acá con todos los sobrecostos que eso implique. Entonces un actor muy importante son los dueños de la tierra. Los urbanizadores compran tierra - a veces compran grandes extensiones, reservas territoriales - y entonces son ellos los que hacen la presión al gobierno municipal: oye sabes que, esta es mi reserva territorial, ponme aquí uso de suelo. [...] En esta administración las condiciones que se impusieron a los urbanizadores son duras para lo que se venía manejando. Ahora un urbanizador que hace fraccionamientos enormes con casas muy pequeñas no tiene cabida. Ya ni siquiera llegan, ya ni siquiera pueden operar [...]. Quienes operan ahora ya no están a las prisas de los créditos puente - que es una de las razones por las que se daban licencias sin estar completo el expediente-, porque tenían que comprar el crédito puente para poder ser acreditados y poder empezar a colocar vivienda. La queja más fuerte que tuvimos - ahorita que lo pienso - no fue de los urbanizadores, fue del INFONAVIT. Empezó a no poder colocar paquetes de vivienda en donde un muy buen porcentaje de los paquetes de vivienda asignados para el Estado de Jalisco eran para Tlajomulco. [...] Las reglas de INFONAVIT también han cambiado: ahora si no se hace todo conforme a los cánones, si no hay una recepción de obra, si no hay habitabilidades, INFONAVIT no paga. Entonces eso obliga a los urbanizadores a medir mejor sus fuerzas. Las habitabilidades, que al final de cuentas es la revisión de las viviendas para ver si están en condiciones para ser habitadas las hacemos nosotros, las hacen nuestros compañeros de obras públicas y no se puede emitir una habitabilidad si no hay una entrega-recepción de las obras de urbanización del fraccionamiento. Entonces esa es una cadena si se concatenan los amarres para terminar con el problema de las viviendas abandonadas y de los fraccionamientos abandonados porque muchos están tirados sin recepciones. Eso para la vivienda nueva, para la que ya está construida es otro problema. Allí es tratar con los urbanizadores, con los que todavía operan les decimos: pues nos arreglas el problema si quieres ver el tema de algún otro fraccionamiento; esa es la manera de presionar y es político, eso no está en la ley. (J. Ramos, comunicación personal, 09 de mayo de 2018).

Ámbito de observación 2: Construcción.

La etapa de construcción, es la segunda de las únicas etapas que están reguladas por el Estado. El instrumento que la rige es la Gaceta Municipal, la cual, remite también a las Normas Oficiales Mexicanas y a las Normas técnicas complementarias de las áreas correspondientes del proyecto.

Ámbito de observación 3: Operación.

En esta etapa se han identificado dos momentos: el de ocupación y el de desempeño. En la ocupación, el usuario empieza a relacionarse con la infraestructura y su entorno, descubre sus nuevos vecinos, hace uso del equipamiento y los servicios públicos más cercanos e inicia un proceso de adaptación que desemboca en aceptación o rechazo hacia su nuevo hábitat. En el momento del desempeño se manifiesta el comportamiento interrelacionado entre los usuarios y el medio ambiente inmediato. Las interrelaciones en la etapa del desempeño hacen posible la evaluación de la calidad ambiental y la evaluación de la habitabilidad para determinar los términos de sostenibilidad o deterioro.

Ámbito de observación 4: Reposición.

Esta fase del ciclo inicia cuando el contexto urbano manifiesta los síntomas del deterioro socioambiental y surge la necesidad de promover estrategias de revitalización urbana para mitigarlo o bien, reponer la VIS abandonada. Cuando por el deterioro se abandonan las viviendas de interés social, la mayor parte de quienes lo hacen se mudan, en el mejor de los casos, a lugares cuyas condiciones de inicio son las mismas que tenía el lugar que están dejando atrás, pero, en ocasiones, ocurre que los usuarios no cuentan con las posibilidades de buscar lo que aparentemente son mejores condiciones de vida y la única opción es quedarse en el sitio deteriorado o buscar alternativas de vivienda informal.

ACE, 14. (42) CC BY-ND 3.0 ES | UPC Barcelona, España | La insostenibilidad de los desarrollos de vivienda de interés social 
[...] hay que ponerle un freno de mano al tema de la vivienda social y que se ocupe lo que está abandonado a través de los programas que está haciendo el INFONAVIT de recuperación de vivienda y varios programas que hay en ese sentido a nivel federal. El tema de recuperación de vivienda es un tema donde el municipio en realidad no se puede meter porque es un tema ya de propiedad privada.

En los casos más extremos, se han hecho procesos de rescate de fraccionamientos, - se han rescatado como 4 o 5 fraccionamientos y ahorita andamos con uno-. Se toma posesión pacífica de las áreas de cesión, se asumen las responsabilidades de los servicios públicos y se hacen créditos fiscales. Si con acciones de recuperación no se logran ocupar las viviendas abandonadas, el peor escenario es la demolición. (J. Ramos, comunicación personal, 09 de mayo de 2018).

\subsection{Resultados con base en el marco metodológico del pensamiento de diseño}

Etapa 1: Empatía con el usuario.

Los resultados de la encuesta sugieren que los habitantes de Chulavista y Santa Fe no están satisfechos con su lugar de residencia. Los primeros cinco ítems de la encuesta se refieren al confort en la vivienda y el conjunto habitacional. Los resultados en la Figura 4 muestran la tendencia entre los valores 1, 2 y 3. La percepción del confort de la muestra encuestada se posicionó entre muy malo y regular con mínima incidencia en valoraciones positivas. No se obtuvo ninguna respuesta con la mayor valoración (5) pero, se obtuvo - aunque no es significativo- que solo el 14\% de la muestra evalúa como bueno (4) los ítems de confort acústico y confort espacial.

Figura 4. Resultados de los ítems 1 a 5 de la encuesta

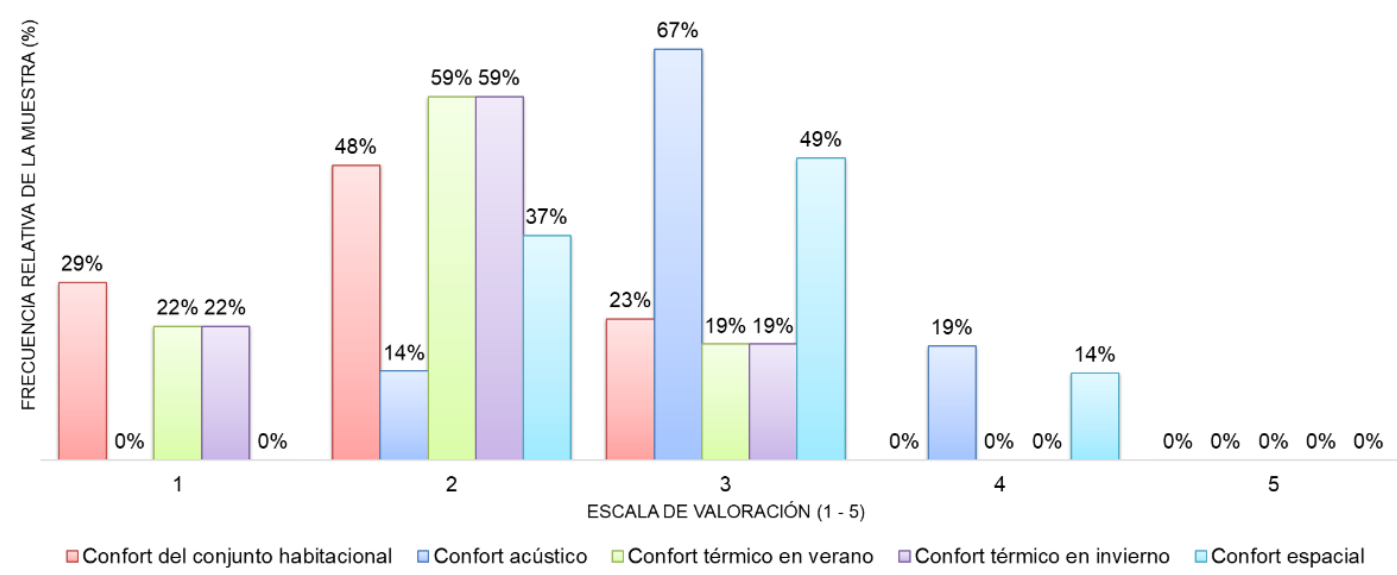

Nota: ver Tabla 4 en sección anterior sobre código para validación de encuesta con base de escala de Likert.

Los resultados de los ítems 6 a 11 se muestran en la Figura 5. Los datos sugieren que los habitantes consideran que el aspecto del conjunto habitacional es regular (3) ó malo (2) y consideran que no habrá cambios en él en los próximos 10 años (2); no se identifican como una comunidad, la participación social registrada es nula (1) o pobre (2); en lo referente al medio ambiente la mayoría de la población se ubica entre la indiferencia (3) y poca preocupación (2); el uso que hacen de las áreas verdes es regular (3) y se obtuvo una valoración mala (2) en cuanto a la percepción de seguridad. 
Figura 5. Resultados de los ítems 6 a 11 de la encuesta

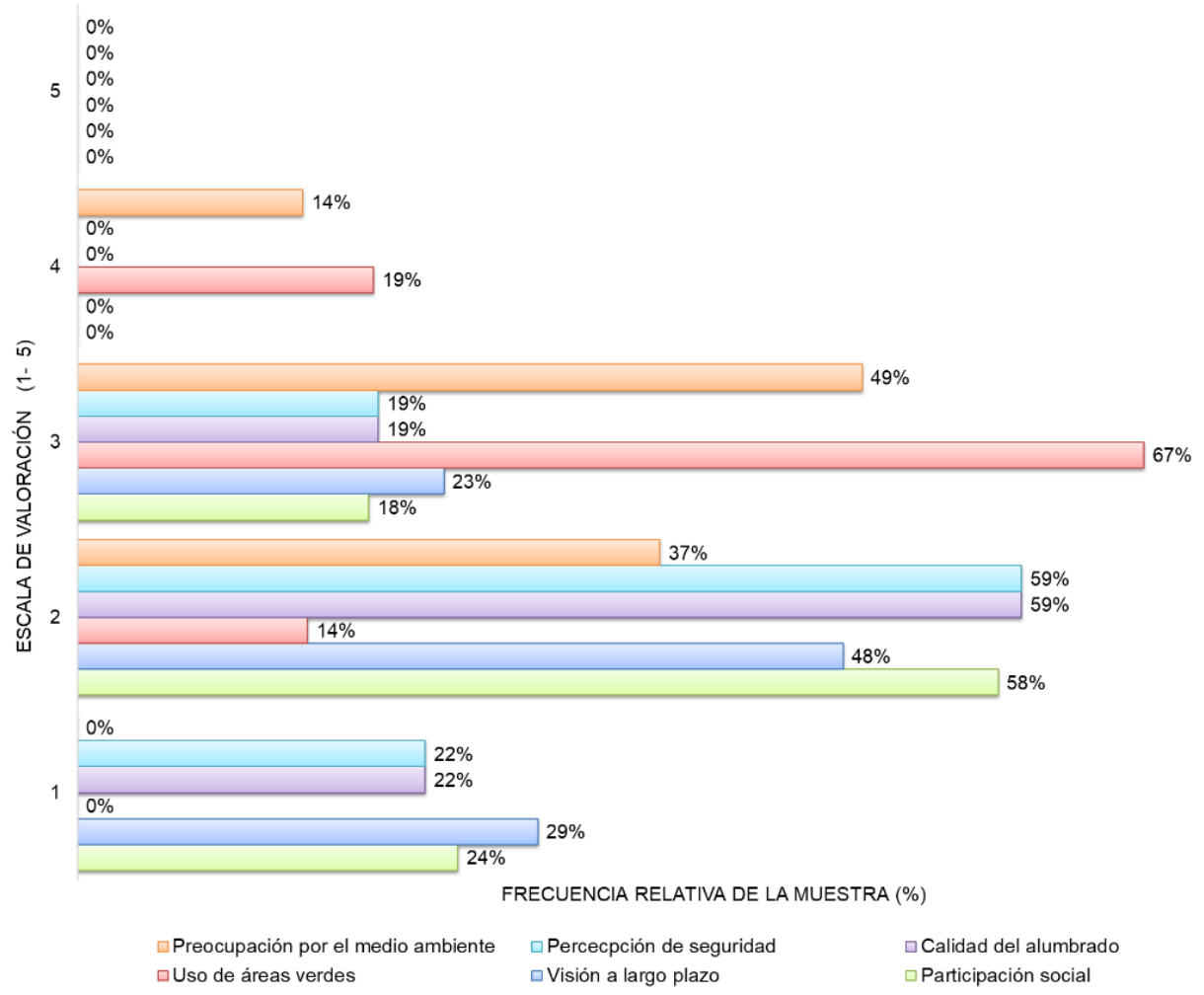

Nota: ver Tabla 4 en sección anterior sobre código para validación de encuesta con base de escala de Likert.

Las respuestas a las preguntas abiertas se agruparon en enunciados que fueron repetidos o que contenían la misma información expresada con diferentes palabras (Figuras 6 y 7).

Figura 6. Resultados de la pregunta: ¿Por qué decidiste comprar una vivienda? / ¿Por qué te gustaría comprar una vivienda?

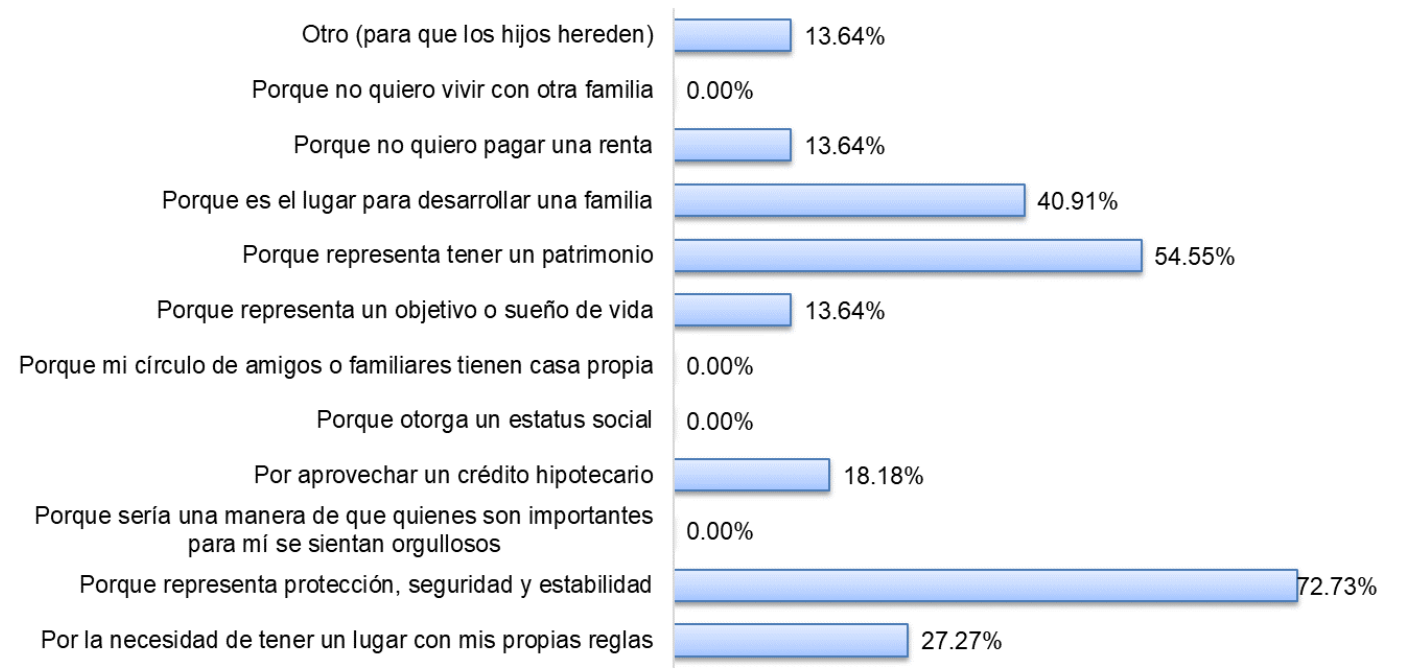

Fuente: Elaboración propia a partir de los resultados de la encuesta.

ACE, 14. (42) CC BY-ND 3.0 ES | UPC Barcelona, España | La insostenibilidad de los desarrollos de vivienda de interés social 
Figura 7. Resultados de la pregunta: ¿Por qué elegiste vivir en el fraccionamiento dónde vives ahora?

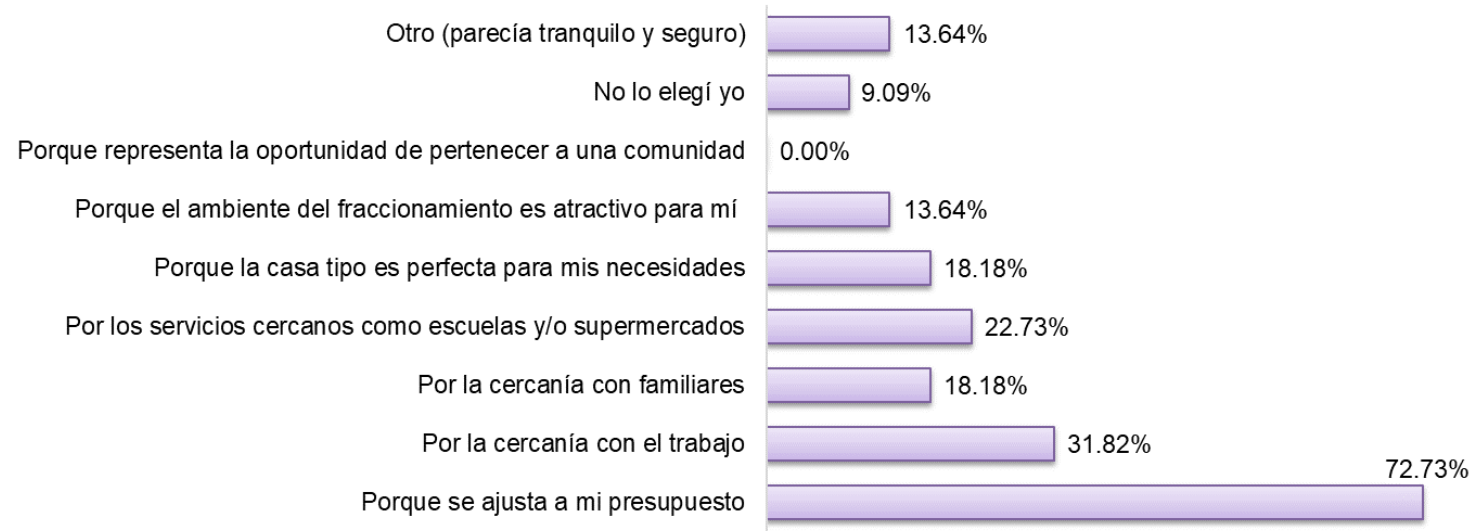

Fuente: Elaboración propia a partir de los resultados de la encuesta.

Etapas 2 y 3: Definición del problema y abstracción de soluciones.

Posterior a la aplicación de la encuesta se llevaron a cabo grupos de enfoque para identificar necesidades y determinar problemas específicos en el área de estudio (ver Tabla 8).

Tabla 8. Niveles de habitabilidad en función de las necesidades y sus satisfactores

\begin{tabular}{|c|c|c|c|c|c|c|}
\hline \multirow{2}{*}{$\begin{array}{l}\text { Necesidad } \\
\text { expresada }\end{array}$} & \multirow{2}{*}{$\begin{array}{l}\text { Satisfactor } \\
\text { identificado }\end{array}$} & \multirow{2}{*}{$\begin{array}{c}\text { Necesidad } \\
\text { humana }\end{array}$} & \multirow{2}{*}{$\begin{array}{l}\text { Necesidad } \\
\text { axiológica - } \\
\text { existencial }\end{array}$} & \multirow[t]{2}{*}{$\mathrm{H}$} & \multicolumn{2}{|c|}{ Relación con encuesta } \\
\hline & & & & & Ítem / fuente & Valor \\
\hline Resguardo & Vivienda & Seguridad & $\begin{array}{l}\text { Subsistencia-Estar } \\
\text { Protección-Estar }\end{array}$ & 5 & $\begin{array}{l}\text { Observación en } \\
\text { sitio }\end{array}$ & 5 \\
\hline Privacidad & $\begin{array}{l}\text { Habitación } \\
\text { individual }\end{array}$ & Fisiológica & $\begin{array}{l}\text { Afecto-Hacer } \\
\text { Afecto-Estar }\end{array}$ & 3 & Confort espacial & 3 \\
\hline $\begin{array}{l}\text { Convivencia } \\
\text { familiar }\end{array}$ & Vivienda & Afiliación & $\begin{array}{l}\text { Afecto-Hacer } \\
\text { Afecto-Estar }\end{array}$ & 3 & Confort espacial & 3 \\
\hline \multirow[t]{2}{*}{ Esparcimiento } & Parques & Afiliación & $\begin{array}{l}\text { Ocio-Estar } \\
\text { Ocio-Hacer }\end{array}$ & 2.5 & $\begin{array}{l}\text { Uso áreas verdes, } \\
\text { Participación social }\end{array}$ & 3,2 \\
\hline & Vivienda & Seguridad & $\begin{array}{l}\text { Afecto-Estar } \\
\text { Afecto-Hacer } \\
\text { Ocio-Estar } \\
\text { Ocio-Hacer }\end{array}$ & 3 & Confort espacial & 3 \\
\hline \multirow[t]{4}{*}{ Movilidad } & Accesibilidad & Seguridad & Libertad-Tener & 1 & \multirow{3}{*}{$\begin{array}{l}\text { Observación en } \\
\text { sitio }\end{array}$} & 1 \\
\hline & $\begin{array}{l}\text { Transporte } \\
\text { público }\end{array}$ & Seguridad & Libertad-Estar & 1 & & 1 \\
\hline & Automóvil & Seguridad & Libertad-Estar & 5 & & 5 \\
\hline & $\begin{array}{l}\text { Cercanía a } \\
\text { sitios de } \\
\text { interés }\end{array}$ & Seguridad & $\begin{array}{l}\text { Protección-Estar } \\
\text { Libertad-Estar }\end{array}$ & $\mathrm{n} / \mathrm{a}$ & $\begin{array}{l}\text { ¿por qué elegiste } \\
\text { este fracc.? }\end{array}$ & $\begin{array}{l}\text { ver } \\
\text { Fig. } 7\end{array}$ \\
\hline \multirow[t]{3}{*}{ Hacer deporte } & Parques & Fisiológica & $\begin{array}{l}\text { Protección-Estar } \\
\text { Libertad-Estar }\end{array}$ & 3 & Uso áreas verdes & 3 \\
\hline & Gimnasio & Fisiológica & Subsistencia-Ser & 5 & \multirow{2}{*}{$\begin{array}{l}\text { Observación en } \\
\text { sitio }\end{array}$} & 5 \\
\hline & $\begin{array}{l}\text { Unidad } \\
\text { deportiva }\end{array}$ & Fisiológica & $\begin{array}{l}\text { Subsistencia-Ser } \\
\text { Protección-Estar }\end{array}$ & 3 & & 3 \\
\hline \multirow[t]{3}{*}{ Seguridad } & $\begin{array}{l}\text { Caseta de } \\
\text { vigilancia }\end{array}$ & Seguridad & Protección-Tener & 1 & \multirow[t]{2}{*}{$\begin{array}{l}\text { Observación en } \\
\text { sitio }\end{array}$} & 1 \\
\hline & $\begin{array}{l}\text { Rondas de } \\
\text { policías }\end{array}$ & Seguridad & Protección-Tener & 1 & & 1 \\
\hline & $\begin{array}{l}\text { Buena } \\
\text { iluminación }\end{array}$ & Seguridad & Protección-Tener & 2 & $\begin{array}{l}\text { Calidad de } \\
\text { alumbrado }\end{array}$ & 2 \\
\hline
\end{tabular}

ACE, 14. (42) CC BY-ND 3.0 ES | UPC Barcelona, España | La insostenibilidad de los desarrollos de vivienda de interés social 


\begin{tabular}{|c|c|c|c|c|c|c|}
\hline & $\begin{array}{l}\text { Fracciona_ } \\
\text { miento } \\
\text { privado }\end{array}$ & Seguridad & $\begin{array}{l}\text { Protección-Ser } \\
\text { Protección-Hacer } \\
\text { Protección-Estar }\end{array}$ & 1 & $\begin{array}{l}\text { Observación en } \\
\text { sitio }\end{array}$ & 1 \\
\hline $\begin{array}{l}\text { Tener un } \\
\text { patrimonio }\end{array}$ & Vivienda & Seguridad & Protección-Tener & $\mathrm{n} / \mathrm{a}$ & \multirow[t]{5}{*}{$\begin{array}{l}\text { ¿por qué decidiste } \\
\text { comprar vivienda? }\end{array}$} & \multirow[t]{5}{*}{$\begin{array}{l}\text { ver } \\
\text { Fig. } 6\end{array}$} \\
\hline Estabilidad & Vivienda & Seguridad & Protección-Tener & $\mathrm{n} / \mathrm{a}$ & & \\
\hline $\begin{array}{l}\text { Formar una } \\
\text { familia }\end{array}$ & Vivienda & Fisiológica & $\begin{array}{l}\text { Subsistencia-Hacer } \\
\text { Afecto-Estar }\end{array}$ & $\mathrm{n} / \mathrm{a}$ & & \\
\hline $\begin{array}{l}\text { Tener un lugar } \\
\text { con mis } \\
\text { propias reglas }\end{array}$ & $\begin{array}{l}\text { Vivienda } \\
\text { propia }\end{array}$ & Seguridad & Libertad-Ser & $\mathrm{n} / \mathrm{a}$ & & \\
\hline $\begin{array}{l}\text { No vivir con } \\
\text { otra familia }\end{array}$ & $\begin{array}{l}\text { Vivienda } \\
\text { propia }\end{array}$ & Fisiológica & Libertad-Ser & $\mathrm{n} / \mathrm{a}$ & & \\
\hline Economía & $\begin{array}{l}\text { Vivienda que } \\
\text { se ajuste a } \\
\text { presupuesto } \\
\text { ó crédito } \\
\text { disponible }\end{array}$ & Seguridad & $\begin{array}{l}\text { Protección-Tener } \\
\text { Libertad-Tener }\end{array}$ & $\mathrm{n} / \mathrm{a}$ & $\begin{array}{l}\text { ¿por qué elegiste } \\
\text { este } \\
\text { fraccionamiento? }\end{array}$ & $\begin{array}{l}\text { ver } \\
\text { Fig. } 7\end{array}$ \\
\hline Tranquilidad & $\begin{array}{l}\text { Regular } \\
\text { niveles de } \\
\text { ruido }\end{array}$ & Fisiológica & Subsistencia-Ser & 2.5 & $\begin{array}{l}\text { Confort acústico, } \\
\text { Seguridad }\end{array}$ & 3,2 \\
\hline $\begin{array}{l}\text { Cuidado de } \\
\text { hijos }\end{array}$ & $\begin{array}{l}\text { Asistencia } \\
\text { social }\end{array}$ & Seguridad & Protección-Tener & 1 & $\begin{array}{l}\text { Observación en } \\
\text { sitio }\end{array}$ & 1 \\
\hline Distraerse & $\begin{array}{l}\text { Actividades } \\
\text { para amas de } \\
\text { casa }\end{array}$ & Seguridad & $\begin{array}{l}\text { Ocio-Estar } \\
\text { Creación-Hacer }\end{array}$ & 1 & $\begin{array}{l}\text { Observación en } \\
\text { sitio }\end{array}$ & 1 \\
\hline
\end{tabular}

Fuente: Elaboración propia.

Notas:

1) Los ítems de preguntas abiertas no fueron evaluados dentro de la escala de Likert, estos ítems tuvieron la función de encontrar motivadores mas no de medir el grado de satisfacción de ese motivador.

2) Se define habitabilidad como el nivel de eficiencia del satisfactor en el área de estudio respecto a la

necesidad expresada. El nivel de habitabilidad $(H)$ fue determinado con base en la siguiente escala:
$1 \quad$ Muy malo
Malo
El satisfactor no existe
Suficiente
El satisfactor existe, pero no se utiliza
Bueno
El satisfactor cumple su función con restricciones
Muy bueno
El satisfactor cumple su función
El satisfactor cumple su función y cubre otras necesidades

Con base en la tabla anterior se extrajeron las necesidades no satisfechas (niveles 1 y 2) y, con apoyo de los grupos de enfoque, se enriqueció la matriz de problemas y se idearon posibles soluciones a la problemática planteada (ver Tabla 9).

Tabla 9. Matriz de problemas y soluciones en el área de estudio

\begin{tabular}{|c|l|}
\hline Descriptor & \multicolumn{1}{|c|}{ Narrativa } \\
\hline Problema & $\begin{array}{l}\text { No se satisface la necesidad de esparcimiento ni afiliación. No existen parques para } \\
\text { realizar actividades al aire libre ni puntos de encuentro con vecinos o familiares fuera de } \\
\text { casa. Las pocas áreas libres "verdes" que existen están en mal estado pues nadie les da } \\
\text { mantenimiento ni están equipadas para actividades de esparcimiento }\end{array}$ \\
\hline Causa & $\begin{array}{c}\text { Se trata de áreas de donación que por reglamento el urbanizador debe dejar libres para } \\
\text { equipamiento público como parques o áreas verdes, no obstante, al ser un bien común sin } \\
\text { administración ni pública ni privada, el área es abandonada y, en ocasiones invadida para } \\
\text { uso privado por algún vecino }\end{array}$ \\
\hline Impacto & $\begin{array}{l}\text { Aislamiento social, vandalismo, inseguridad, lotes baldíos que se vuelven tiraderos de } \\
\text { basura }\end{array}$ \\
\hline Solución & $\begin{array}{l}\text { Formación de comité vecinal para la administración del bien común una vez que el } \\
\text { municipio se encargue de equiparlo y dejarlo adecuado para esparcimiento }\end{array}$ \\
\hline Problema & $\begin{array}{l}\text { No se satisface la necesidad de accesibilidad. Las banquetas son invadidas por autos, son } \\
\text { muy angostas y la gente tiene que caminar por la calle donde transitan vehículos }\end{array}$ \\
\hline
\end{tabular}

ACE, 14. (42) CC BY-ND 3.0 ES | UPC Barcelona, España | La insostenibilidad de los desarrollos de vivienda de interés social 


\begin{tabular}{|c|c|}
\hline Causa & $\begin{array}{l}\text { La urbanización de predios para habitación está regida por la máxima rentabilidad, en este } \\
\text { sentido el urbanizador se guía por los parámetros mínimos de dotación de infraestructura } \\
\text { estipulados en la normatividad municipal. Bajo esta lógica, el ancho de banquetas } \\
\text { especificado en reglamento es insuficiente }\left(0.90 \mathrm{~m} \text { ); el área de crecimiento en } \mathrm{m}^{2} \text { para la }\right. \\
\text { vivienda también es insuficiente y esto obliga a construir en el área libre para cajón de } \\
\text { estacionamiento (1) }\end{array}$ \\
\hline Impacto & Riesgo de accidentes de tránsito, inseguridad y tensión entre vecinos \\
\hline Solución & Modificación a los parámetros de equipamiento público en la urbanización para habitación \\
\hline Problema & No se satisface la necesidad de movilidad \\
\hline Causa & $\begin{array}{l}\text { No se identifican rutas de transporte urbano suficientes y constantes que conecten el } \\
\text { conjunto habitacional con el resto de la ciudad. Se identifican lugares que incluso son } \\
\text { inaccesibles por medio de transporte público }\end{array}$ \\
\hline Impacto & $\begin{array}{l}\text { Aislamiento, abandono de vivienda, inversión excesiva en tiempos de traslado, compra de } \\
\text { vehículos privados usados, invasión de calles para aparcamiento }\end{array}$ \\
\hline Solución & $\begin{array}{l}\text { Establecer por ley que los conjuntos habitacionales cuenten con conectividad suficiente con } \\
\text { el resto de la ciudad por medio de transporte público eficiente y seguro }\end{array}$ \\
\hline Problema & $\begin{array}{l}\text { No se satisface la necesidad de seguridad. No hay buen alumbrado público, no existen } \\
\text { casetas de vigilancia ni cuerpos de seguridad que estén vigilando la zona periódicamente. }\end{array}$ \\
\hline Causa & $\begin{array}{l}\text { Iluminación en calles y áreas públicas insuficiente, alto número de viviendas abandonadas y } \\
\text { lotes baldíos, no se percibe cohesión social }\end{array}$ \\
\hline Impacto & Percepción de inseguridad, vandalismo, robos frecuentes, actos de violencia doméstica \\
\hline Solución & $\begin{array}{l}\text { Los vecinos opinan que esto se solucionaría haciendo los fraccionamientos cerrados, } \\
\text { reforzando iluminación, con caseta de vigilancia y pagando por seguridad }\end{array}$ \\
\hline Problema & $\begin{array}{l}\text { No se satisface la necesidad de tranquilidad. Existe contaminación acústica al interior de las } \\
\text { casas }\end{array}$ \\
\hline Causa & $\begin{array}{l}\text { No existen barreras anti-sonoras como cortinas de árboles, no hay buffer de } \\
\text { amortiguamiento entre viviendas, el material de construcción de las casas no es aislante y, } \\
\text { los vecinos desconocen las normas de urbanidad }\end{array}$ \\
\hline Impacto & Estrés, acentuación de problemas domésticos, privación de descanso \\
\hline Solución & $\begin{array}{l}\text { Modificación a los parámetros de colindancia en la urbanización para habitación, } \\
\text { reglamentar el uso de materiales de construcción en materia de aislamiento acústico y } \\
\text { promoción de las normas de urbanidad entre los vecinos }\end{array}$ \\
\hline Problema & $\begin{array}{l}\text { No se satisface la necesidad de esparcimiento para personas encargadas del hogar. No } \\
\text { existen lugares cercanos a los que puedan asistir a algún curso o actividad recreativa donde } \\
\text { puedan convivir }\end{array}$ \\
\hline Causa & $\begin{array}{l}\text { Falta de equipamiento público. Lejanía de los desarrollos habitacionales respecto al centro } \\
\text { de la ciudad }\end{array}$ \\
\hline Impacto & Estrés, aislamiento, aumento de tiempo de ocio que es utilizado en ver TV \\
\hline Solución & $\begin{array}{l}\text { Establecer por reglamento que los desarrollos habitacionales sean equipados con centro de } \\
\text { actividades de esparcimiento o que haya uno cercano al desarrollo }\end{array}$ \\
\hline Problema & $\begin{array}{l}\text { El grupo identifica problemas de abastecimiento de agua y electricidad. Hay cortes de agua } \\
\text { por lo menos dos veces a la semana y la presión de abastecimiento no es suficiente. } \\
\text { También hay cortes de electricidad y generalmente el alumbrado público no está prendido. }\end{array}$ \\
\hline Causa & $\begin{array}{l}\text { Desconocida. Se hacen planteamientos como: no hubo dictamen de factibilidad de agua } \\
\text { potable, la infraestructura no es adecuada para asegurar presión suficiente, no se calculó } \\
\text { bien el volumen de abastecimiento para soportar a la población }\end{array}$ \\
\hline Impacto & $\begin{array}{l}\text { Condiciones de insalubridad, pérdida de tiempo, fricciones en el hogar o con vecinos, } \\
\text { percepción de inseguridad }\end{array}$ \\
\hline Solución & $\begin{array}{l}\text { Solicitar apoyo a la municipalidad para asegurar el abastecimiento y la presión requerida y/o } \\
\text { pedir apoyo para depósitos de agua de reserva }\end{array}$ \\
\hline Problema & $\begin{array}{l}\text { El grupo identifica problemas de movilidad. Las viviendas están alejadas del centro, de los } \\
\text { lugares de trabajo, de servicios de salud o escuelas de nivel medio superior y superior. No } \\
\text { hay suficientes rutas de transporte público o incluso los autobuses no realizan las rutas } \\
\text { completas. La movilidad entre guetos se dificulta porque existen bardas entre ellos y se } \\
\text { obliga a tomar caminos más largos. }\end{array}$ \\
\hline Causa & $\begin{array}{l}\text { Insuficiencia en el servicio de transporte público, vialidades no adecuadas para tráfico de } \\
\text { autobuses, barreras físicas entre guetos }\end{array}$ \\
\hline Impacto & $\begin{array}{l}\text { Pérdida de tiempo, sensación de inseguridad, limitaciones en los horarios para desplazarse, } \\
\text { impulso por abandonar el lugar de residencia y mudarse a otro de mejor ubicación o con } \\
\text { conectividad suficiente }\end{array}$ \\
\hline Solución & $\begin{array}{l}\text { Solicitar apoyo a la municipalidad para asegurar servicio de transporte público con mayor } \\
\text { número de rutas y equipamiento urbano mínimo por normativa para este servicio }\end{array}$ \\
\hline
\end{tabular}

Fuente: Elaboración propia.

ACE, 14. (42) CC BY-ND 3.0 ES | UPC Barcelona, España | La insostenibilidad de los desarrollos de vivienda de interés social 
Etapa 4: Conceptualización de un modelo.

Para efectos de esta investigación, el prototipo considerado fue el estado actual de la vivienda de interés social en el área de estudio. Los resultados en los grupos de enfoque y la aplicación de la encuesta muestran que las principales inquietudes se concentran en contar con espacios donde puedan vivir con libertad, ya no decir comodidad sino contar con infraestructura y servicios básicos urbanos como la seguridad al acceso de agua potable y el aseguramiento de la movilidad; condiciones que deben cumplirse para contar con vivienda digna. Se identifican como principales problemas los siguientes: 1) la inseguridad, 2) la falta de rutas de transporte, 3) los cortes recurrentes de los servicios urbanos, 4) que sus casas están alejadas del centro de la ciudad o sus lugares de trabajo y, 5) las barreras físicas entre guetos que los hacen perder tiempo en sus desplazamientos o bien, que los obligan a transitar por zonas que preferirían evitar pues los perciben como lugares inseguros. Las virtudes que identifican son: 1) Que es vivienda propia, 2) Cuando no es propia, el costo de la renta es bajo, 3) Se han re-activado algunos lugares por intervención de la municipalidad a través del presupuesto participativo. El tiempo libre generalmente lo pasan en casa y les gustaría contar con instalaciones deportivas cercanas, con casetas de vigilancia, estancias para el cuidado de los hijos y espacios donde las amas de casa puedan tener actividades recreativas. No se identifican como una comunidad y aunque se reconoce la existencia de un comité vecinal y el fomento municipal para la participación ciudadana, no se percibe cohesión social. Los principales medios de transporte utilizados por los residentes son el transporte público (autobús urbano) y el automóvil (propio o servicio de taxi). Este último lo utilizan para llegar a los lugares donde no se tiene acceso al transporte público y, algunos casos se registraron inaccesibles a determinadas horas por la resistencia del servicio de taxis a entrar a sectores específicos por la sensación de inseguridad. Se registraron algunos casos de personas que llegaron a Chulavista buscando mejores condiciones de vida al abandonar otro fraccionamiento; no obstante, las condiciones con las que se encontraron en Chulavista fueron las mismas. Expresan también la necesidad de privacidad y creen conveniente que cada miembro de la familia tenga una habitación, aunque sea de dimensiones mínimas pues en muchos casos en una vivienda hay más de dos familias conviviendo y no cuentan con espacios de esparcimiento familiar ni lugares ni tiempo para criar a los hijos (Figuras 8, 9 y 10).

Figura 8. Chulavista Sector IX. Tlajomulco de Zúñiga, Jalisco, México

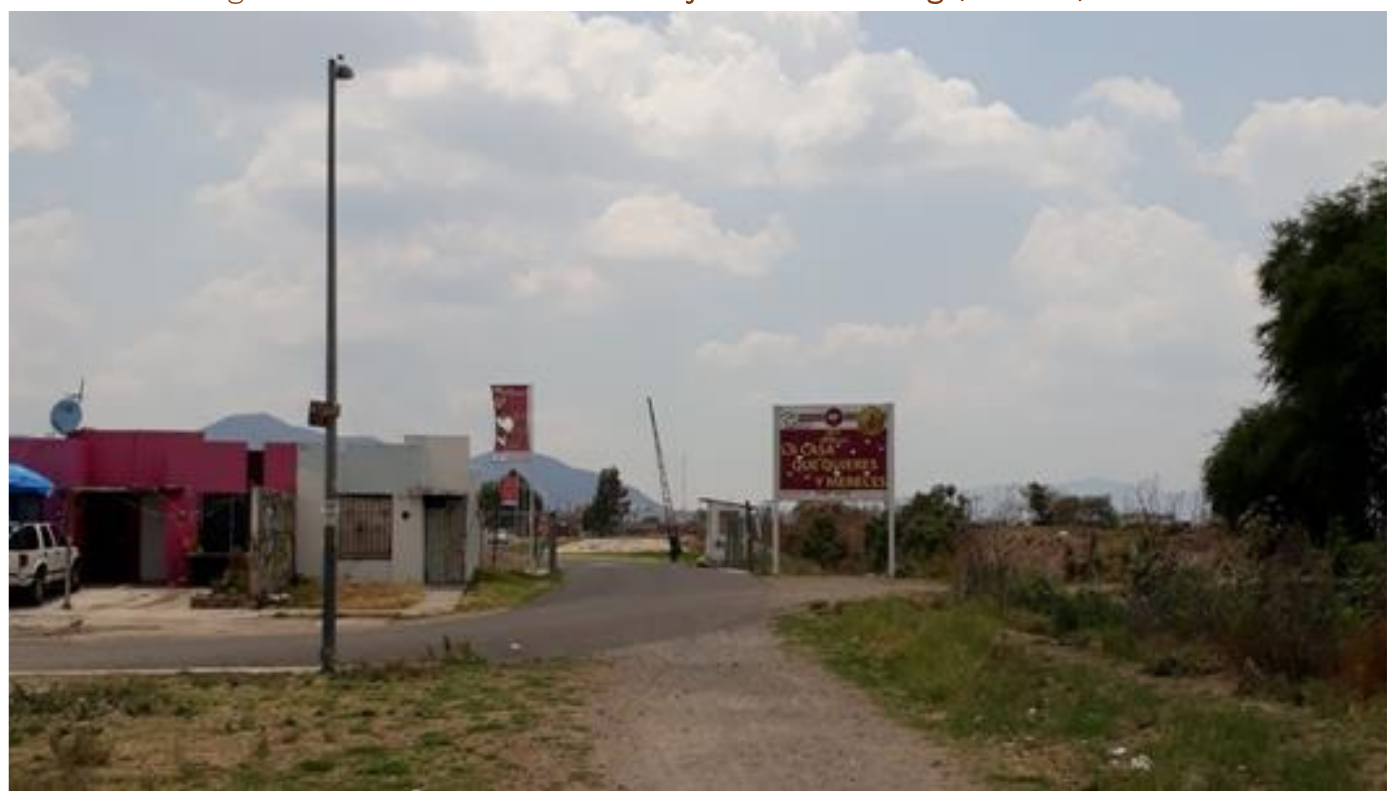

Nota: Publicidad "La casa que quieres y mereces". Acceso a fraccionamiento. Fecha de captura: 11 de mayo de 2018. Fuente: Fotografía del autor.

ACE, 14. (42) CC BY-ND 3.0 ES | UPC Barcelona, España | La insostenibilidad de los desarrollos de vivienda de interés social en México: una aproximación desde el pensamiento de diseño. Caso de estudio: Tlajomulco de Zúñíga, Jalisco. DOI: http://dx.doi.org/10.5821/ace.14.42.8256 


\section{ACE Architecture, City and Environment}

E-ISSN 1886-4805

Figura 9. Chulavista Sector IX. Tlajomulco de Zúñiga, Jalisco, México

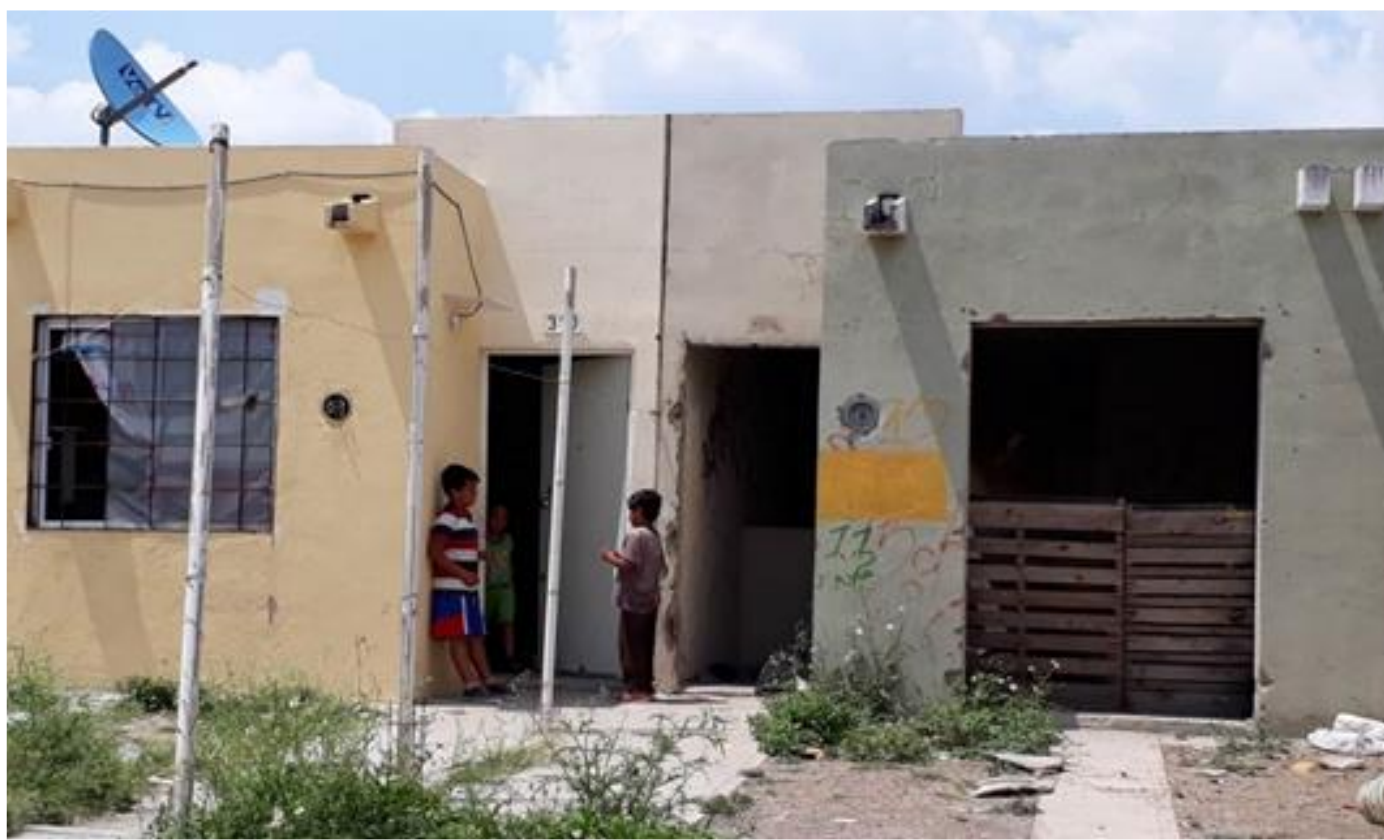

Nota: Espacios de convivencia de niños. Registro durante la mañana de un día hábil. Fecha de captura: 11 de mayo de 2018. Fuente: Fotografía del autor.

Figura 10. Chulavista Sector IX. Tlajomulco de Zúñiga, Jalisco, México

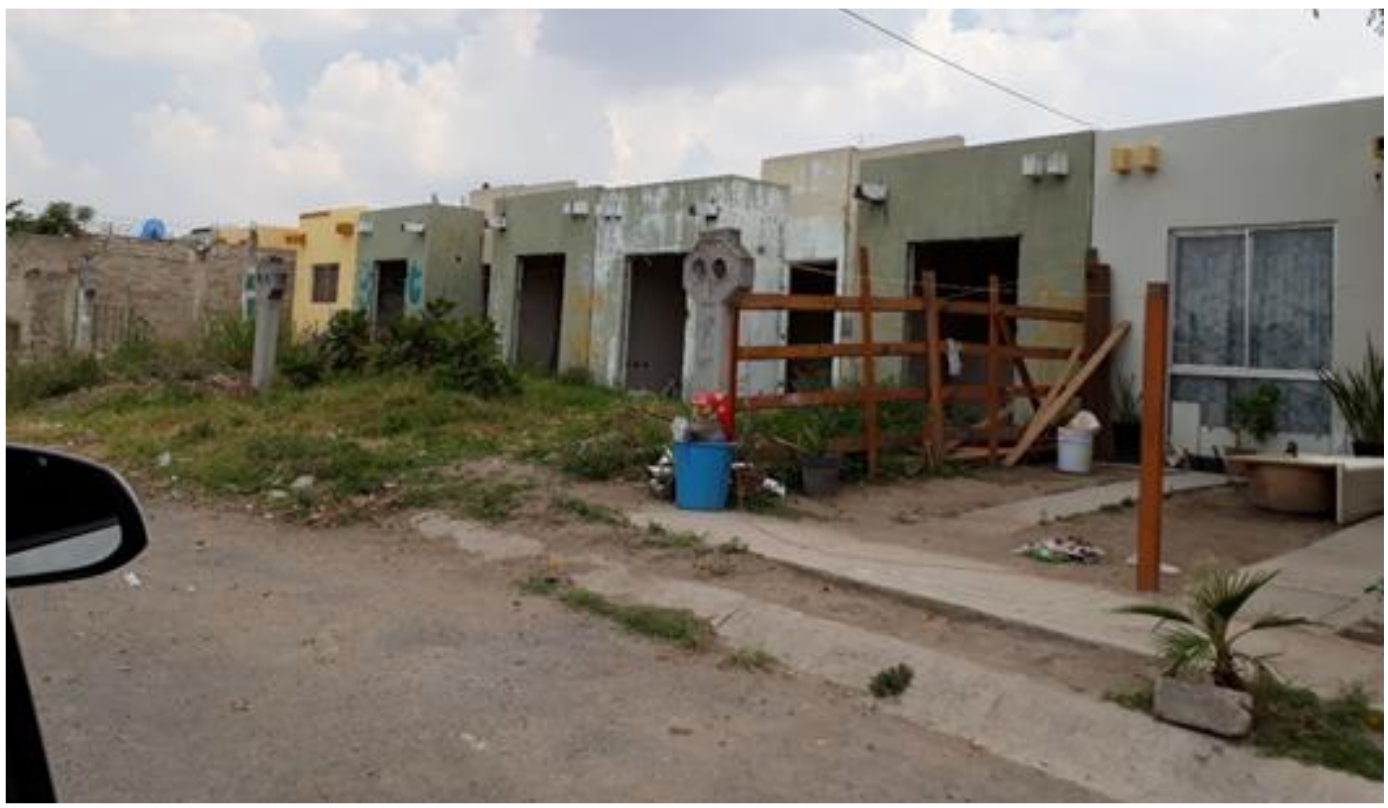

Nota: Una casa habitada junto a casas abandonadas vandalizadas. Fecha de captura: 11 de mayo de 2018. Fuente: Fotografía del autor.

Etapa 5: Evaluación del desempeño - calidad ambiental en el área de estudio.

El resultado del análisis de estos elementos en el área de estudio respecto a la normatividad local y los estándares más elevados para obtener el ideal de bienestar están reflejados en la Figura 11.

ACE, 14. (42) CC BY-ND 3.0 ES | UPC Barcelona, España | La insostenibilidad de los desarrollos de vivienda de interés social 
Figura 11. Evaluación de criterios de calidad del medio ambiente natural (Q1)

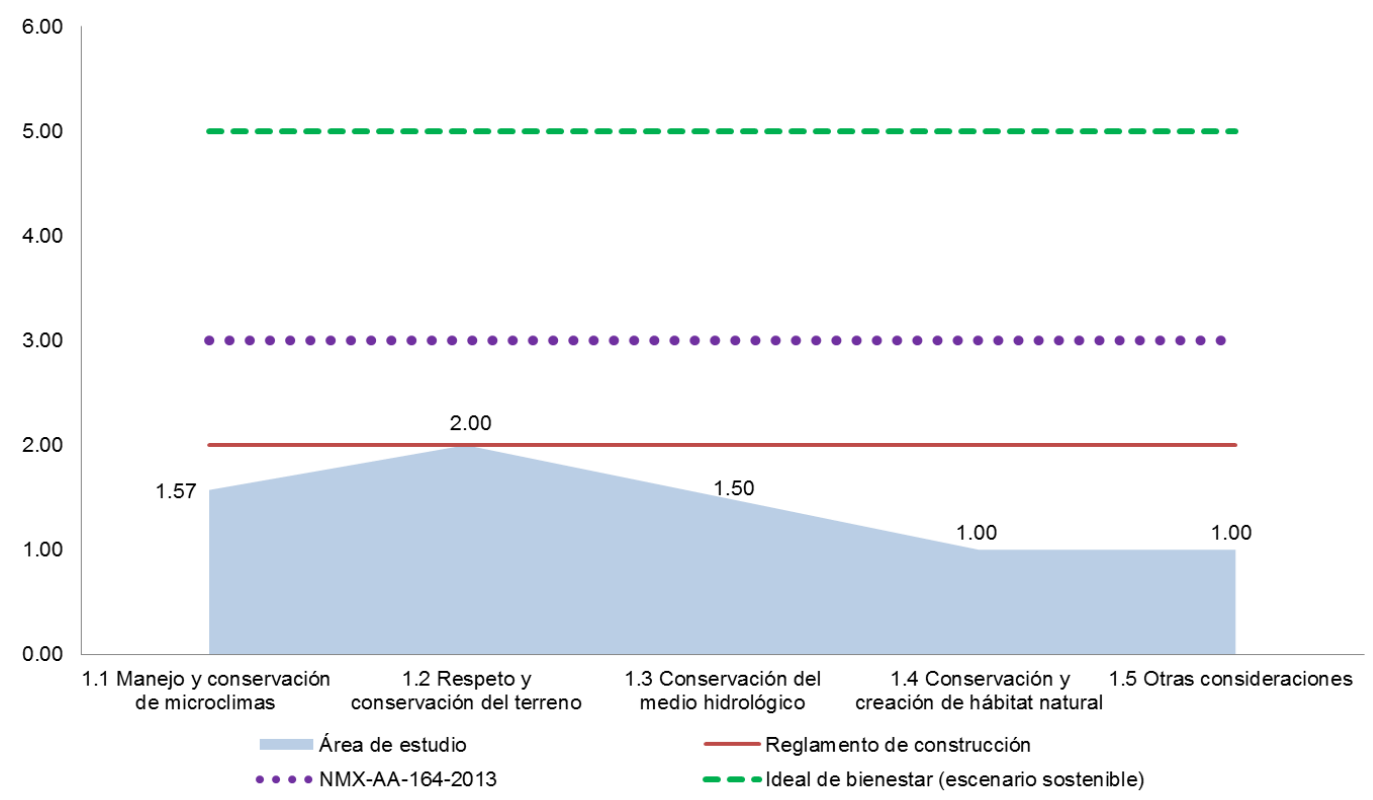

Fuente: Elaboración propia.

Nota: La escala de medición tiene base en los valores siguientes:

1 En deterioro Parámetros inferiores a la normatividad local

2 Insuficiente Parámetros contenidos en normatividad local

3 Suficiente Parámetros mínimos y de carácter obligatorio dentro de la NMX-AA-164-2013

4 Óptimo Parámetros superiores a la NMX, pero inferiores a lo máximo establecido en la herramienta CASBEE-UD para un medio ambiente sostenible

5 Ideal de bienestar Parámetros CASBEE-UD para un medio ambiente sostenible

La figura anterior nos muestra que la calidad del medio ambiente natural en el área de estudio es insuficiente $(\bar{x}=1.41)$; no obstante, los valores de los criterios evaluados no están muy lejos de lo requerido en la normatividad local. En este sentido, los datos sugieren que la normatividad debe revisarse para re-establecer los parámetros que rigen los desarrollos urbanos de vivienda en materia de calidad ambiental.

Calidad de los servicios urbanos.

Se identificaron como principales problemas los siguientes: 1) Falta de rutas de transporte, 2) La dificultad para desplazarse a pie y la inaccesibilidad para personas con discapacidad, 3) Largas distancias a los puntos de interés para desarrollo de la vida cotidiana y barreras físicas que incrementan distancias y obligan a los peatones a transitar por zonas que se perciben como riesgosas o inseguras, 4) Cortes recurrentes de los servicios urbanos y, 5) Aunque existen diferentes servicios de abasto de suministros dentro del polígono de estudio, las distancias a los servicios públicos son largas y de difícil acceso en términos de transporte público.

La Figura 12 muestra que la calidad de los servicios urbanos en el área de estudio es insuficiente ( $\bar{x}$ $=1.73$ ). El criterio 2.2 referente al desempeño de los servicios de transporte de encuentra en el punto de tendencia al deterioro. La movilidad es uno de los principios básicos de la libertad individual; sin embargo, no se están respetando los parámetros mínimos establecidos por reglamento para asegurar estos servicios. Se encontró que el tiempo promedio de desplazamiento en transporte público hacia sitios de interés oscila entre los 30 y 80 minutos en viaje sencillo (Figura 13).

ACE, 14. (42) CC BY-ND 3.0 ES | UPC Barcelona, España | La insostenibilidad de los desarrollos de vivienda de interés social 
Figura 12. Evaluación de criterios de calidad de los servicios urbanos (Q2)

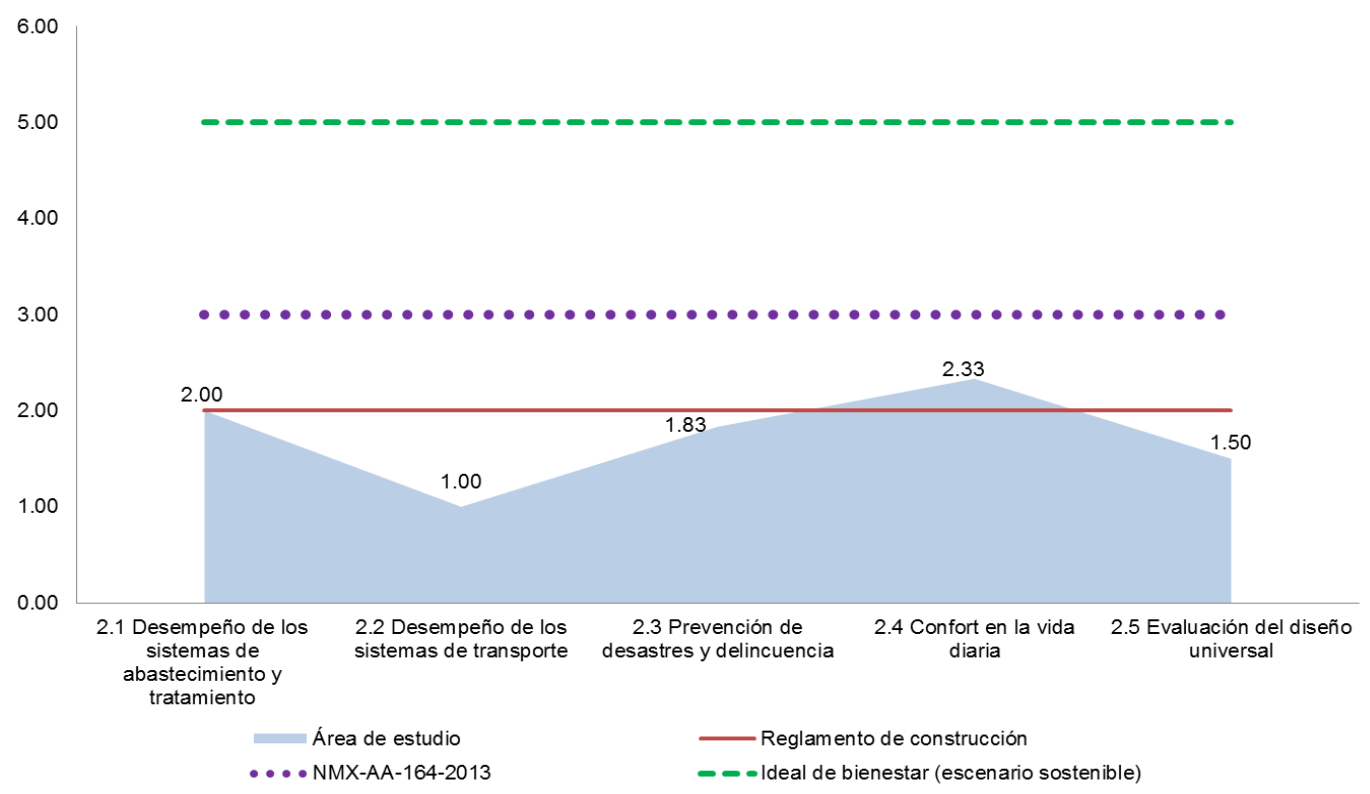

Fuente: Elaboración propia.

Nota: La escala de medición tiene base en los valores siguientes:

1 En deterioro Parámetros inferiores a la normatividad local

2 Insuficiente Parámetros contenidos en normatividad local

3 Suficiente Parámetros mínimos y de carácter obligatorio dentro de la NMX-AA-164-2013

4 Óptimo Parámetros superiores a la NMX, pero inferiores a lo máximo establecido en la

herramienta CASBEE-UD para un medio ambiente sostenible

5 Ideal de bienestar Parámetros CASBEE-UD para un medio ambiente sostenible

Figura 13. Desplazamientos en la ciudad (destinos-tiempos solo ida-medios de transporte)

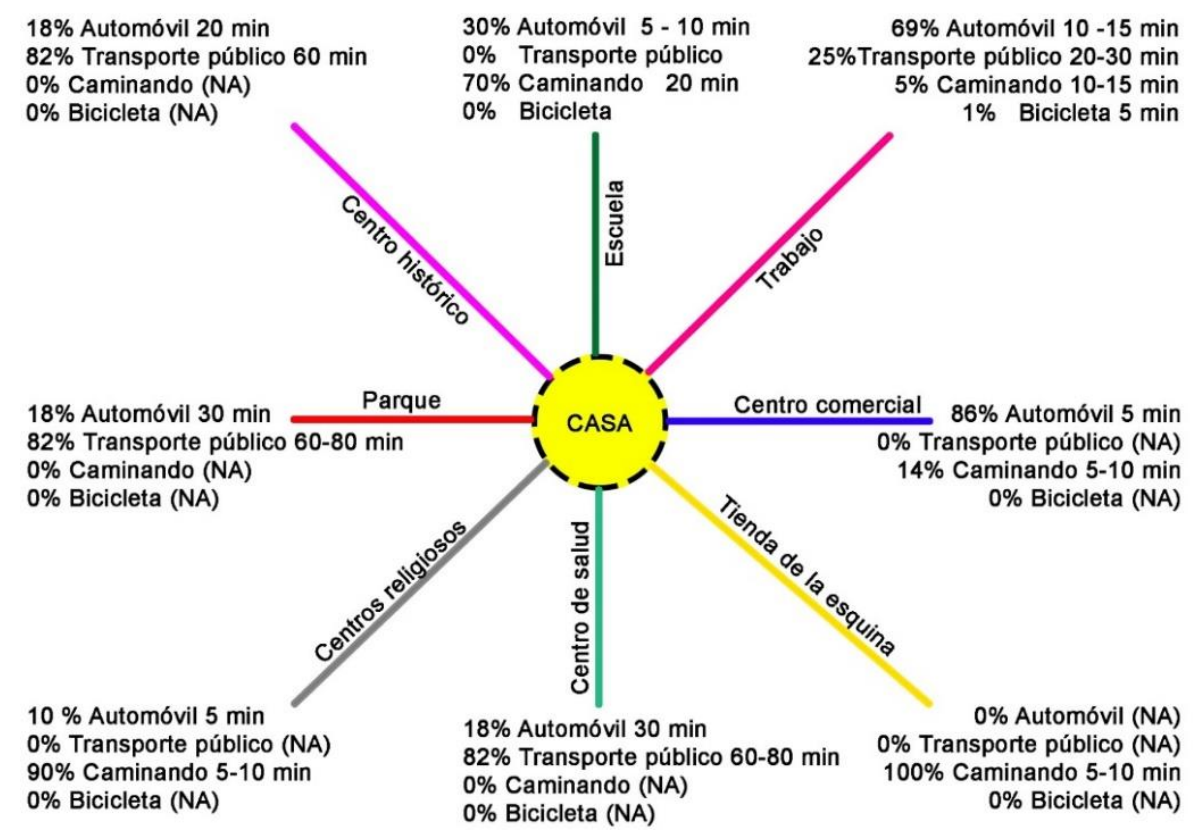

Fuente: Elaboración propia. Fecha de elaboración: 27 de mayo de 2018, modificado 26 de julio de 2019.

ACE, 14. (42) CC BY-ND 3.0 ES | UPC Barcelona, España | La insostenibilidad de los desarrollos de vivienda de interés social 
Contribución a la comunidad.

Los resultados se exponen en la Figura 14.

Figura 14. Evaluación de criterios de contribución a la comunidad (Q3)

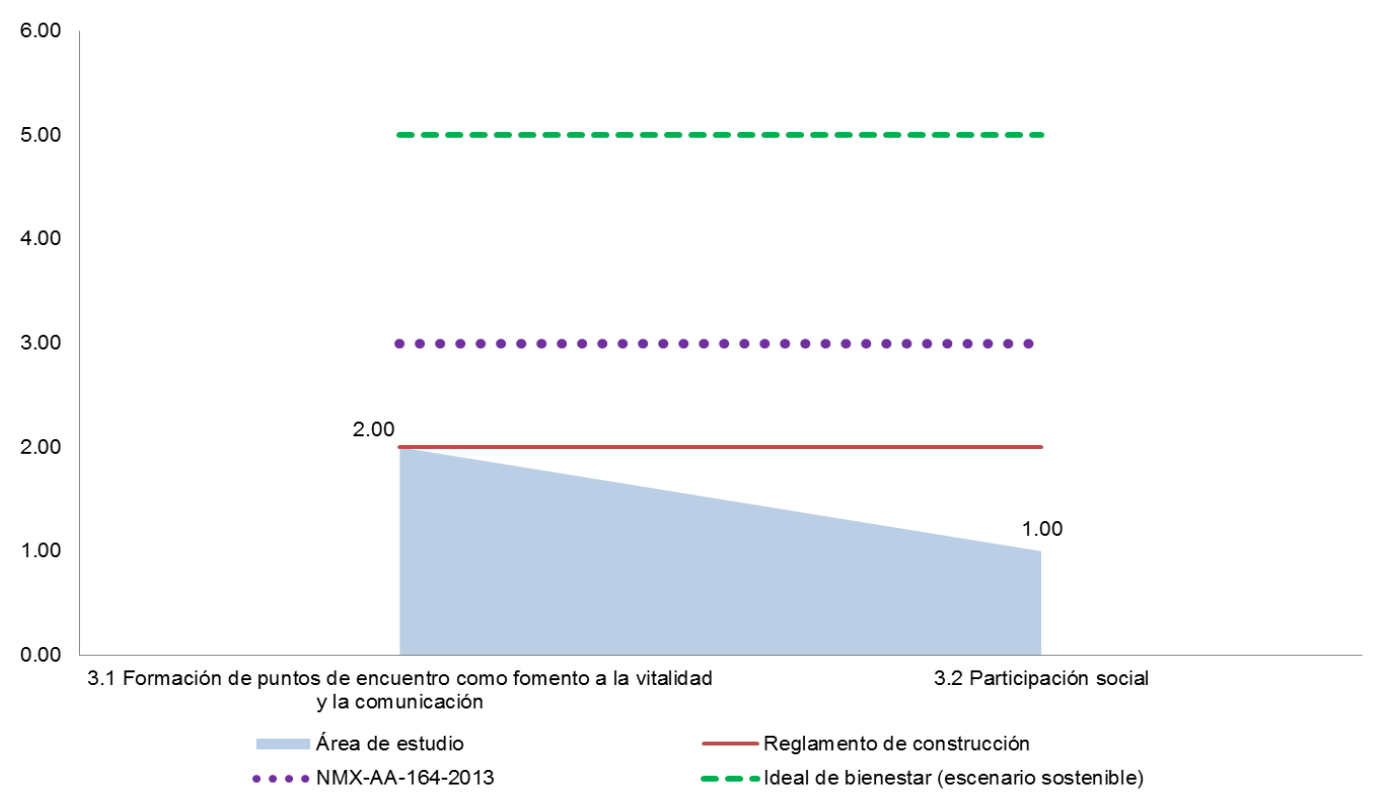

Fuente: Elaboración propia.

Nota: La escala de medición tiene base en los valores siguientes:

1 En deterioro Parámetros inferiores a la normatividad local

2 Insuficiente Parámetros contenidos en normatividad local

3 Suficiente Parámetros mínimos y de carácter obligatorio dentro de la NMX-AA-164-2013

4 Óptimo Parámetros superiores a la NMX, pero inferiores a lo máximo establecido en la

herramienta CASBEE-UD para un medio ambiente sostenible

5 Ideal de bienestar Parámetros CASBEE-UD para un medio ambiente sostenible

Se encontró que el área de estudio cuenta con las áreas destinadas por reglamento para parques o áreas verdes; sin embargo, su uso dista del objetivo. Estos espacios lejos de representar un punto de encuentro son lugares abandonados que se vuelven tiraderos de basura, lugares de vandalismo o bien, son invadidos por algún vecino para uso particular. No se identificaron redes de participación social y aunque se reconoce la existencia de un comité vecinal y el fomento municipal para la participación ciudadana, no se percibe cohesión social.

\section{Conclusiones}

En México, la gestión y construcción de vivienda de interés social se ha vuelto objeto de especulación y ha perdido su denotación promotora del ejercicio del derecho social a disfrutar de una vivienda digna. Los impactos socio-ambientales de su producción comprometen la calidad de vida de sus habitantes y la sostenibilidad del medio ambiente que los contiene. La literatura muestra una fuerte relación oferta-demanda pese a que se reportan escenarios de abandono de este tipo de vivienda. Así, el presente trabajo representa una propuesta metodológica para abordar la insostenibilidad urbano-ambiental de los desarrollos de vivienda de interés social en México. El marco de referencia del pensamiento de diseño incluye la visión del consumidor mediante la aplicación de técnicas de las ciencias sociales y la integración holística de la gestión de proyectos. A partir de este marco, se esquematizó el ciclo de gestión de proyectos y se extrajeron necesidades de habitabilidad de la población estudio, así como los problemas más representativos en las unidades de estudio. Se

ACE, 14. (42) CC BY-ND 3.0 ES | UPC Barcelona, España | La insostenibilidad de los desarrollos de vivienda de interés social 25 en México: una aproximación desde el pensamiento de diseño. Caso de estudio: Tlajomulco de Zúñiga, Jalisco. DOI http://dx.doi.org/10.5821/ace.14.42.8256 
identificaron algunos factores que hacen insostenible el bienestar en la vida cotidiana de las personas que habitan en viviendas de interés social. Estos factores son:

\subsection{Con base en el marco del ciclo de gestión de producción de proyectos}

- Las decisiones que se tomaron en la planeación son determinantes en la insostenibilidad de los proyectos de vivienda de interés social. Estas decisiones - correspondientes a la definición de los parámetros de planeación urbana para la vivienda - no fueron analizadas a profundidad y sólo se repitieron los criterios que históricamente fueron aplicados a la producción de la VIS sin considerar si los criterios eran o no los adecuados. La VIS - por lo menos hasta el momento de la realización de esta investigación-, es abordada como un producto de fabricación en serie que no considera las características del entorno ni asegura el disfrute de una vivienda digna.

- La ubicación y características de estos desarrollos responde a una lógica de mercado y procesos especulativos más que a la obligación del Estado de facilitar el acceso a la vivienda digna. Una vivienda digna va más allá de los $\mathrm{m}^{2}$ habitables, la vivienda digna debe asegurar fácil acceso a servicios públicos como: movilidad, educación, salud, esparcimiento y administración.

- Existen fallas administrativas en los procesos de gestión de la VIS que merman la calidad de la infraestructura. Se mencionan aquí dos ejemplos: 1) Se otorgaron autorizaciones para desarrollo de vivienda sin expedientes completos, sin factibilidades otorgadas o con factibilidades dadas a juicio y, 2) Hay casos donde no se lleva a cabo el proceso de entrega-recepción de las obras entre urbanizador y municipio, esto impacta directamente en las habitabilidades que deberían asegurarse sobre la vivienda previo a la ocupación.

- Los parámetros de los criterios de sostenibilidad en los reglamentos de construcción en México están desactualizados y, la Norma Mexicana analizada, aunque considera lo necesario para aseguras niveles óptimos de bienestar, sigue siendo de carácter voluntario.

- No existen mecanismos de regulación de la calidad del hábitat urbano en las etapas de ocupación y desempeño de la infraestructura de vivienda de interés social.

- Pese a que la vivienda digna es un derecho compuesto, los instrumentos de gestión abordan a la VIS para procurar únicamente el acceso a una vivienda ${ }^{9}$ pero no para asegurar su calidad ni la satisfacción de las necesidades de los ocupantes.

- El ciclo de gestión de producción de la vivienda de interés social debe considerar la prospección de las necesidades de la población objetivo para satisfacer las necesidades de la generación contemporánea y, que también, sea flexible para sostener los cambios en las dinámicas de sus ocupantes y del entorno inmediato a lo largo del tiempo. Los resultados obtenidos comparten la perspectiva de (Lynch, 2014) cuando habla sobre la necesidad de gestionar la decadencia considerando que toda infraestructura, al igual que cualquier proceso evolutivo, es un ciclo; es decir, se debe gestionar y planear también considerando el deterioro como un componente inexorable del proceso evolutivo y de su ciclo de vida.

\subsection{Con base en el marco metodológico del pensamiento de diseño}

- Los resultados encontrados refuerzan el argumento de Pisarello (2004) que define a la vivienda digna como "un derecho compuesto cuya vulneración acarrea la de otros derechos fundamentales [...]” (Pisarello, 2004, pág. 259). En esta investigación se encontró que hay necesidades humanas fisiológicas, de afiliación y seguridad cuya satisfacción es pobremente cubierta bajo las condiciones actuales de la infraestructura de la VIS ${ }^{10}$. Las necesidades axiológicas-existenciales vulneradas por esta insatisfacción son: ocio-estar, ocio-hacer, libertad-tener, libertad-estar,

\footnotetext{
${ }^{9}$ Entiéndase por acceso a la vivienda a la procuración de instrumentos legales y financieros para adquirir el bien inmueble.

${ }^{10}$ Entiéndase por condiciones de la VIS a la calidad del bien inmueble, a la calidad del conjunto habitacional, al nivel de acceso a servicios urbanos y a las relaciones socio-territoriales con el resto de la ciudad.
}

ACE, 14. (42) CC BY-ND 3.0 ES | UPC Barcelona, España | La insostenibilidad de los desarrollos de vivienda de interés social 26 en México: una aproximación desde el pensamiento de diseño. Caso de estudio: Tlajomulco de Zúñiga, Jalisco. DOI http://dx.doi.org/10.5821/ace.14.42.8256 
protección-tener, protección-ser, protección-hacer, protección-estar, subsistencia-ser y creación-tener.

- Se encontró que los niveles de habitabilidad más baja son los correspondientes con las necesidades que no son satisfechas. Los satisfactores identificados para estas necesidades son: dotación de parques para esparcimiento, accesibilidad a servicios urbanos y conectividad con los servicios de la ciudad mediante transporte público eficiente y seguro, equipamiento con casetas de vigilancia, existencia de rondas de policía, aseguramiento de buena iluminación en calles y áreas públicas, idealmente que el fraccionamiento sea privado, regulación de niveles de ruido al interior de las casas, dotación de servicio de asistencia social para cuidado de los hijos y dotación de servicios para realizar actividades destinadas a personas encargadas del hogar.

- Se identificó que el principal motivador para adquirir una vivienda es porque representa protección, seguridad, estabilidad y tener un patrimonio, en contraste, dos de las necesidades encontradas como insatisfechas corresponden justamente a lo referente a protección y seguridad.

- Las áreas de donación - que teóricamente son para equipamiento urbano-, carecen de administración ya sea pública o privada, por tanto, paulatinamente estos espacios comunes (bienes comunes) tienden al deterioro: se convierten en tiraderos de basura, son susceptibles a invasión, impactan negativamente la imagen del conjunto o se vuelven focos de delincuencia y pueden incrementar la sensación de inseguridad.

- La infraestructura que actualmente se construye en México para la dotación de vivienda de interés social no considera las necesidades de los habitantes. Este tipo de vivienda en serie está pensado en la máxima rentabilidad sobre el suelo urbano y está lejos de considerar los perfiles de la gente que las ocupa. Ejemplo: Hacen uso de este tipo de infraestructura familias de diferentes composiciones: unipersonal, parejas sin hijos, parejas con hijos o bien, hay casos de más de una familia habitando en una vivienda. En este sentido, si la infraestructura no facilita la satisfacción de las necesidades en el presente, tampoco lo hará en futuros cambios de composición familiar o cambio de necesidades; así, con el paso del tiempo la infraestructura de vivienda de interés social se vuelve obsoleta e insostenible.

- Se identificó que la razón por la que eligen el fraccionamiento que habitan es porque es lo que se ajusta a su presupuesto. Este argumento es correspondiente con la lógica del valor del suelo expuesta por el director de ordenamiento territorial de Tlajomulco de Zúñiga: "[...] y allí es donde empieza el circulo vicioso porque conforme uno se va acercando a la ZMG los terrenos se van haciendo más caros y ya no pueden entrar dentro de los costos y presupuestos de los fraccionamientos de interés social, entonces tienen que hacerse más lejos". (J. Ramos, comunicación personal, 09 de mayo de 2018).

- La ubicación de los conjuntos habitacionales es determinante en el nivel de satisfacción del ocupante. Una buena ubicación asegurará la satisfacción de necesidades como son: seguridad, movilidad, conectividad, esparcimiento, afiliación, salud y educación. En consecuencia, la infraestructura de la VIS debe ser fuertemente vinculada con la ciudad y sus servicios sin que ello represente un incremento en los costos de venta.

- La normatividad referente a construcción y equipamiento urbano debe fortalecerse en materia de desempeño ambiental apoyándose con los lineamientos establecidos en la NMX-AA-164-SCFI2013. Los datos sugieren que la tendencia del desempeño de la calidad del medio ambiente natural es de insuficiente a en deterioro. Es necesario hacer notar que los conjuntos habitacionales cumplen con parte de los requisitos minimos requeridos en los reglamentos municipales, por ello la necesidad del fortalecimiento de la normativa. Esta recomendación es congruente con los resultados del ISV evaluado por el Centro Mario Molina en 2012.

- En cuanto a la calidad del medio ambiente natural se debe poner especial atención a la conservación y creación de hábitat, lo cual está relacionado con la conservación del medio hidrológico y el manejo y conservación de micro-climas.

ACE, 14. (42) CC BY-ND 3.0 ES | UPC Barcelona, España | La insostenibilidad de los desarrollos de vivienda de interés social en México: una aproximación desde el pensamiento de diseño. Caso de estudio: Tlajomulco de Zúñiga, Jalisco. DOI: http://dx.doi.org $/ 10.5821 /$ ace.14.42.8256 
- Respecto a la calidad de los servicios urbanos, el de mayor impacto negativo es lo referente al desempeño de los sistemas de transporte, al diseño no adecuado para inclusión de personas con discapacidades, adultos mayores o niños y a la prevención de desastres y delincuencia.

- Por último, dentro de la categoría de contribución a la comunidad, el criterio con menor puntuación fue la participación social y en segundo, la formación de puntos de encuentro como fomento a la vitalidad y la comunicación. Con base en los datos recabados en la investigación, en este punto se puede concluir que, aunque por reglamento si se establecen áreas de donación para áreas verdes y equipamiento urbano, estas áreas al no ser administradas suelen ser abandonadas o invadidas a menos que el municipio fomente la participación y re-activación de estos espacios.

La intervención del Estado sobre las políticas que regulan la gestión inmobiliaria ha disminuido en el transcurso del tiempo y la responsabilidad sobre la calidad de la vivienda y su entorno está diluida entre el municipio, los urbanizadores, el agente constructor y una normatividad débil en cuestiones de bienestar. Este trabajo - además de evidenciar algunas fallas administrativas en el proceso de gestión de producción de la VIS que impactan directamente en los niveles de habitabilidad-, representa una extracción de necesidades de una muestra de la población. Esta información puede servir como base para la proyección de espacios habitables de vivienda de interés social y su relación con los servicios que ofrece la ciudad. Asimismo, se enriquece con las argumentaciones de Mattioli (2019), Elinbaum (2018) y Pisarello (2004), y contribuye con la argumentación para abordar la gestión de la VIS desde la complejidad, como construcción social y como un derecho compuesto dada su función multidimensional.

\section{Agradecimientos}

A la Universidad Nacional Autónoma de México, al Posgrado en Ciencias de la Sostenibilidad y al Consejo Nacional de Ciencia y Tecnología. Agradecimiento especial a las personas residentes del área de estudio, quienes brindaron su apoyo y tiempo para hacer realidad esta investigación; a los funcionarios del gobierno municipal de Tlajomulco de Zúñiga, quienes compartieron experiencias e información, y a los revisores anónimos de este artículo, quienes enriquecieron notablemente el trabajo con su participación.

\section{Autoría}

La primera autora ha diseñado y desarrollado la investigación, la recolección y análisis de datos, toma de fotografías, redacción y confección de tablas y figuras; el segundo autor ha revisado la estructura del artículo, el objeto de estudio, la hipótesis y objetivos y la tercera autora ha revisado el marco de referencia, la metodología y la bibliografía.

Conflicto de intereses: Los autores declaran que no hay conflicto de intereses.

\section{Bibliografía}

Alaminos Chica, A. y Castejón Costa, J. L. (2006). Elaboración, análisis e interpretación de encuestas, cuestionarios y escalas de opinión. Alicante, España: Universidad de Alicante.

Brown, T. y Wyatt, J. (2010). Design Thinking for Social Innovation. Development Outreach, 12(1), 2943. DOI: https://doi.org/10.1596/1020-797X 12129

ACE, 14. (42) CC BY-ND 3.0 ES | UPC Barcelona, España | La insostenibilidad de los desarrollos de vivienda de interés socia 
Canales, F. (2017). Vivienda colectiva en México: el derecho a la arquitectura. Barcelona, España: Gustavo Gili, S.L.

Castro Ramírez, M. E.; Romero Castillo, L. I.; Borre Aguilera, C. A. y Anguiano Reyes, C. A. (2001). Habitabilidad, medio ambiente y ciudad. Revista Ciudades, 13(51), 10-18.

Cervantes, J. F.; Maya, E. y Martínez, J. G. (2008). Evaluación de la habitabilidad de la vivienda social producida industrialmente en México. Ciudad de México, México: UNAM, Centro de Investigaciones y Estudios de Posgrado. Facultad de arquitectura.

Centro de Investigación para el Desarrollo Sostenible, CIDS. (2019). Evaluación cualitativa de la vivienda y su entorno (Ecuve). Recuperado de http://cii.infonavit.org.mx/IndicesdeCalidad/ecuve.html

Comisión Nacional de Vivienda, CONAVI. (2019). ¿Qué hacemos? Recuperado de: https://www.gob.mx/conavi/que-hacemos

Elinbaum, P. (2018). La construcción social del Planeamiento Urbano: elementos para la investigación empírica y la reflexión desde la práctica. ACE: Architecture, City and Environment, 12(36), 15-38. DOI: 10.5821/ace.12.36.4729

Esqueda Atayde, R.; López-León, R.; Martínez de la Peña, A.; Rivera Díaz, A.; Rodríguez Morales, L.; Tapia Mendoza, A.; Tiburcio García, C.; Torres Maya, R. y Villalobos Saldaña, S. (2017). ¿Design thinking? Una discusión a nueve voces. Ciudad de México, México: Ars Optika Editores S.A de C.V.

Esquivel Hernández, M. T.; Maya Pérez, E. y Cervantes Borja, J. (2005). La promoción privada y los grandes conjuntos habitacionales: nuevas modalidades de acceso a la vivienda. Scripta Nova: revista electrónica de geografía y ciencias sociales, 9(194), Recuperado de http://www.ub.edu/geocrit/sn/sn194-21.htm

García Peralta, B. (2010). Vivienda social en México (1940-1999): Actores públicos, económicos y sociales. Cuadernos de vivienda y urbanismo, 3(5), 34-49. DOI: https://doi.org/10.11144/Javeriana.cvu3$\underline{5 . v s m a}$

García Peralta, B. (2016). La vivienda y el Estado mexicano durante el siglo XX. Un enfoque desde la economía política. Ciudad de México, México: UNAM, Instituto de Investigaciones Sociales.

Hernández, R. G.; Herrera Aguado, A. L.; Cruz Sosa, E. M. y García Castro, P. E. (2009). Los créditos INFONAVIT (México) ¿Prestaciones sociales o negocios? Revista Internacional Administración \& Finanzas, 2(1), 41-56. Recuperado de http://www.theibfr2.com/RePEc/ibf/riafin/riaf-v2n1-2009/RIAFv2N1-2009-4.pdf

Institute for Building Environment and Energy Conservation, IBEEC. (2018). Comprehensive Assessment System for Built Environment Efficiency for Urban Development (CASBEE-UD). Recuperado de http://www.ibec.or.jp/CASBEE/english/toolsE urban.htm

Instituto de Información Estadística y Gegráfica de Jalisco, IIEGJ. (2017). Sistema de consulta de información sociodemográfica por colonias de Jalisco, 2010. Recuperado de: https://www.iieg.gob.mx/contenido/PoblacionVivienda/ciudadesmedias/tlajo.html

Centro Mario Molina. (2012). Evaluación de la sustentabilidad de la vivienda en México-2012. Recuperado de http://centromariomolina.org/ciudades-sustentables/evaluacion-de-lasustentabilidad-de-la-vivienda-en-mexico/ 
Sociedad Hipotecaria Federal, SHF. (2015). Estado Actual de la Vivienda en México 2015. Recuperado de https://www.gob.mx/shf/documentos/estado-actual-de-la-vivienda-en-mexico-eavm-2015 Sociedad Hipotecaria Federal, SHF. (2018). Estado Actual de la Vivienda en México 2018. Recuperado de https://www.gob.mx/shf/documentos/estado-actual-de-la-vivienda-en-mexico-eavm-2018

Lefebvre, H. (2013). La producción del espacio. [trad.] Emilio Martínez. Madrid, España: Capitán Swing Libros, S.L.

Ley de Aguas Nacionales. Secretaría General (México). Diario Oficial de la Federación, de 1 de diciembre de 1992. Última Reforma DOF 06-01-2020. Recuperado de http://www.diputados.gob.mx/LeyesBiblio/pdf/16 060120.pdf

Ley de Aprovechamiento Sustentable de la Energía. Secretaría General (México). Diario Oficial de la Federación, de 28 de noviembre de 2008. Recuperado de https://www.senado.gob.mx/comisiones/energia/docs/marco LASE.pdf

Ley General de Asentamientos Humanos, Ordenamiento Territorial y Desarrollo Urbano. Secretaría General (México). Diario Oficial de la Federación, de 28 de noviembre de 2016. Última Reforma DOF 06-01-2020. Recuperado de http://www.diputados.gob.mx/LeyesBiblio/pdf/LGAHOTDU 060120.pdf

Ley General de Equilibrio Ecológico y Protección al Ambiente. Secretaría General (México). Diario Oficial de la Federación, de 28 de enero de 1988. Última Reforma DOF 09-01-2015. Recuperado de http://biblioteca.semarnat.gob.mx/janium/Documentos/Ciga/agenda/DOFsr/148.pdf

Ley General para la Prevención y Gestión Integral de Los Residuos. Secretaría General (México). Diario Oficial de la Federación, de 08 de octubre de 2003. Última Reforma DOF 19-01-2018. Recuperado de http://www.diputados.gob.mx/LeyesBiblio/pdf/263 190118.pdf

Lynch, K. (2014). Echar a perder. Un análisis del deterioro. Barcelona, España: Gustavo Gili, S.L.

Martínez Ibarra, A. e Ibarra Salazar, J. (2017). Los determinantes de la satisfacción residencial en México. Estudios Demográficos y Urbanos, 32(2), 283-313. DOI: http://dx.doi.org/10.24201/edu.v32i2.1635

Maslow, A. (2012). Motivación y personalidad. Madrid, España: Ediciones Díaz de Santos, S.A.

Mattioli, L. (2019). El buen vivir y el ordenamiento territorial. Una transición socio-ecológica en construcción. ACE: Architecture, City and Environment, 13(39), 37-62. DOI: 10.5821/ace.13.39.5357

Max-Neef, M.; Elizalde, A. y Hopenhayn, M. (2010). Desarrollo a escala humana. Una opción para el futuro. Madrid, España: Biblioteca CF+S.

McGuirk, J. (2015). Ciudades radicales. Un viaje a la nueva arquitectura latinoamericana. Madrid, España: Turner Noema.

Naciones Unidas, UN. (2018). Población. Recuperado de https://www.un.org/es/sections/issuesdepth/population/index.html

NMX-AA-164-SCFI-2013. Norma Mexicana para la Edificación sustentable - Criterios y requerimientos ambientales mínimos. Secretaría de Economía (México). Diario Oficial de la Federación, de 04 de septiembre de 2013.2 Recuperado de http://biblioteca.semarnat.gob.mx/janium/Documentos/Ciga/agenda/DOFsr/D03156.pdf 
ONU-Hábitat. (2019). Elementos de una vivienda adecuada. Recuperado de https://www.onuhabitat.org.mx/index.php/elementos-de-una-vivienda-adecuada

Pisarello, G. (2004). Vivienda para todos: un derecho en (de) construcción: el derecho a una vivienda digna y adecuada como derecho exigible. Barcelona, España: Icaria Editorial.

Puebla Cadena, C. (2002). Del intervencionismo estatal a las estrategias facilitadoras. Cambios en la política de vivienda en México, 1972-1994. Ciudad de México, México: El Colegio de México.

Terraza, H.; Rubio Blanco, D. y Vera, F. (2016). De ciudades emergentes a ciudades sostenibles. Comprendiendo y proyectando las metrópolis del siglo XXI. Providencia, Chile: Ediciones ARQ.

Terrazas Pastor, R. A. (2009). Modelo conceptual para la gestión de proyectos. Perspectivas, 12(24), 165-188. Recuperado de https://www.redalyc.org/articulo.oa?id=425942160009 